\title{
Localization of Calbindin-D28k and Calretinin in the Brain of Dermophis Mexicanus (Amphibia: Gymnophiona) and Its Bearing on the Interpretation of Newly Recognized Neuroanatomical Regions
}

\author{
Ruth Morona Jesús María López Agustín González \\ Department of Cell Biology, Faculty of Biology, University Complutense of Madrid, Madrid, Spain
}

\author{
Key Words \\ Calcium-binding proteins $\cdot$ Evolution $\cdot$ Diencephalon . \\ Amphibians $\cdot$ Immunohistochemistry
}

\begin{abstract}
The analysis of the distribution of the calbindin-D28k and calretinin immunoreactive (CBir and CRir) systems recently described in the brain of anuran and urodele amphibians was very useful for the interpretation of many otherwise indistinct brain regions and cell masses. In the present study we have followed a similar approach to investigate the distribution of CBir and CRir cell bodies and fibers in the brain of Dermophis mexicanus, a member of the much neglected third amphibian order of gymnophionans. The pattern of distribution obtained showed particular characteristics in Dermophis, such as the existence of abundant CRir elements in the olfactory bulbs and CBir and CRir cell populations in pallial areas. The distinct distribution of the two proteins allowed the tentative identification of currently described subregions, mainly in the amygdaloid complex and hypothalamic areas. The analysis of the diencephalon and brainstem distribution framed in the neuromeric model highlighted common traits with other amphibians but also specific features. Therefore, the immunohistochemical detection of calciumbinding proteins has served to discern cell populations and has helped to demonstrate neuronal heterogeneity. However, it should be pointed out that a straightforward compari-
\end{abstract}

son based only on the presence of these proteins should not be made due to the great variability observed in well-established homologous regions in the brain of different vertebrates, as evidenced within the class Amphibia.

Copyright $\odot 2011$ S. Karger AG, Basel

\section{Introduction}

Extant amphibians comprise 3 lineages - salamanders (Urodela or Caudata), frogs and toads (Anura), and caecilians (Gymnophiona, Apoda, or Caecilia) - which contain more than 6,000 species. The little known order Gymnophiona comprises 171 species of circumtropical distribution [Frost, 2007]. They are limbless, burrowing animals with worm-like bodies that move like snakes and posses a sense organ unique among vertebrates, i.e. the tentacle, which is probably involved in tactile and chemoreceptive functions, and their visual system was regarded as nonfunctional or degenerated [Engelhardt, 1924; Noble, 1931; Taylor, 1968; Storch and Welsch, 1973; Nussbaum and Wilkinson, 1989; Duellman and Trueb, 1994; Himstedt, 1996]. Interestingly, morphology- and molecule-based studies have disagreed profoundly regarding extant amphibian relationships. Most morphological and paleontological studies of living and fossil amphibians support the hypothesis that salamanders and frogs are sister lineages (the Batrachia hypothesis) and that caeci-

\section{KARGER}

Fax +4161306 1234

E-Mail karger@karger.ch

www.karger.com
(C) 2011 S. Karger AG, Basel

0006-8977/11/0774-0231\$38.00/0

Accessible online at:

www.karger.com/bbe
Dr. Agustín González

Departamento de Biología Celular

Facultad de Biología, Universidad Complutense

ES-28040 Madrid (Spain)

Tel. +34 1394 4977, E-Mail agustin@bio.ucm.es 
Abbreviations used in figures 1-10

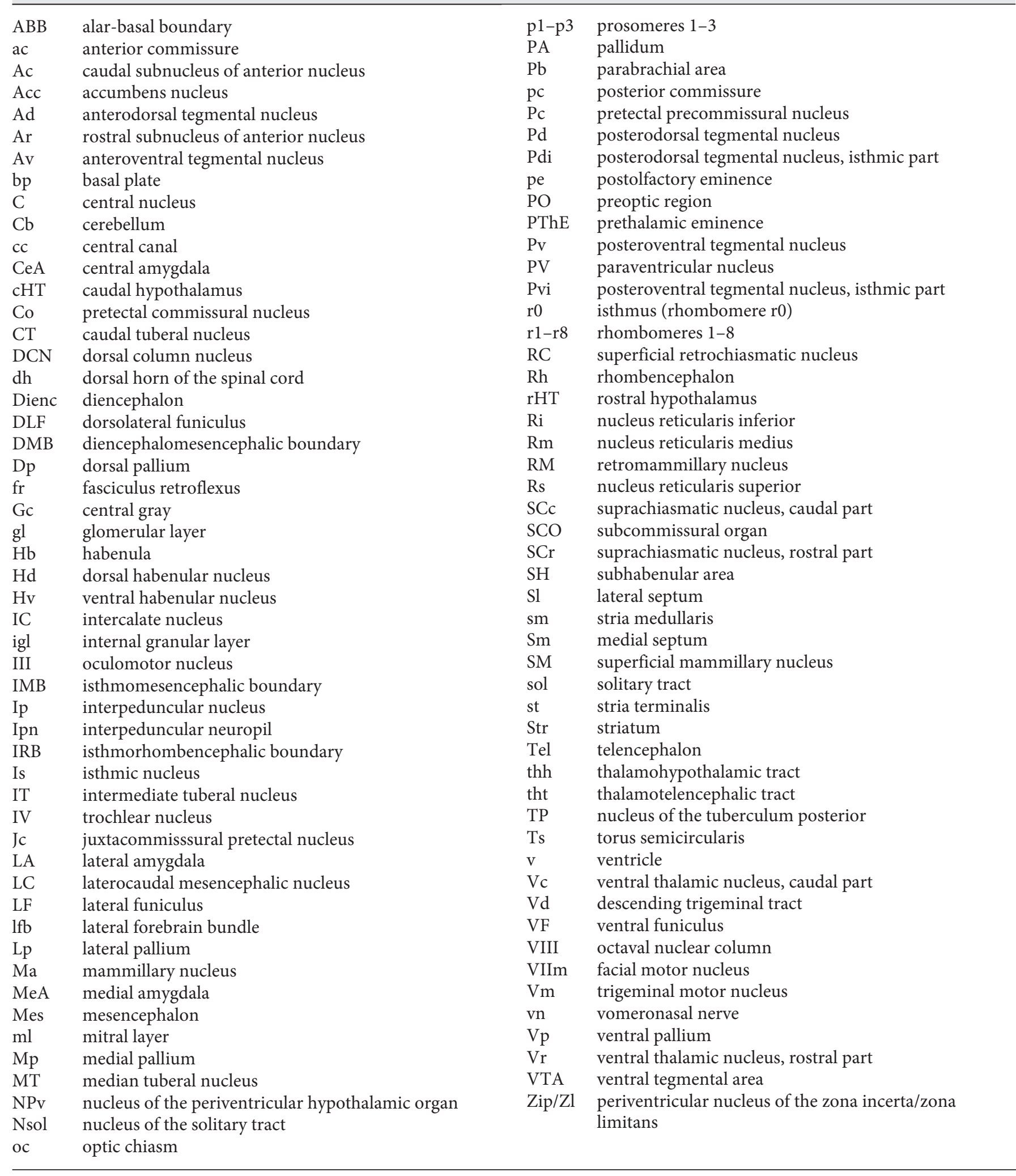


lians are more distantly related [Milner, 1988; Trueb and Cloutier, 1991; Duellman and Trueb, 1994]. In contrast, interpretations of molecular data based on nuclear and mitochondrial rRNA sequences suggested that salamanders and caecilians are sister groups, with the exclusion of frogs [Larson and Wilson, 1989; Hedges et al., 1990, 1993; Bolt, 1991; Hay et al., 1995; Feller and Hedges, 1998]. However, subsequent comparative studies of the complete mitochondrial genomes of several gymnophionans supported the monophyly of living amphibians with respect to other living groups of tetrapods, and a sister group relationship of salamanders and frogs [Zardoya and Meyer, 2001; San Mauro et al., 2004].

In contrast to the relatively well-investigated neuroanatomy of anurans and urodeles, the gymnophionans have received little attention in the neuroscientific literature, not least because of the difficulty to breed them in the laboratory, thereby restricting the number of test animals. The brain development of frogs and salamanders differs considerably. The brains of frogs are morphologically much more complex than those of salamanders [Roth et al., 1993; ten Donkelaar, 1998a, b]. On the other hand, salamanders and caecilians show similarities in many features of brain development [Roth et al., 1993]. In both orders, the identification of individual nuclei in the brain is arduous since cell segregation is hardly present in any brain region. In addition, major structures, such as the cerebellum, are absent or currently unrecognized in the gymnophionan brain [Kühlenbeck, 1922, 1975, 1978]. These shared patterns would seemingly contradict the Batrachia hypothesis. However, the simple brain morphology of salamanders may be a secondarily derived condition associated with an increase in genome, cell size, and paedomorphic evolution [Roth et al., 1993, 1997]. In fact, the available experimental studies conducted in the brain of gymnophionans have shown many complex features of its organization that could not be detected on the basis of cytoarchitecture alone and that were distinct from those of anurans and urodeles. These features of gymnophionans include, among others, the presence of particular cholinergic and somatostatinergic cell groups in the thalamus, the presence of a well-developed mesencephalic group of dopaminergic cells, the existence of complex cholinergic and nitrergic cell populations in the basal ganglia, or the particular arrangement of the motor nuclei in the brainstem [González and Smeets, 1994, 1997; Pinelli et al., 1997; Hilscher-Conklin et al., 1998; Ebersole and Boyd, 2000; Ebersole et al., 2001; Sánchez-Camacho et al., 2001; González et al., 2002a, b; López et al., 2006, 2007]. Therefore, any study that at-

$\mathrm{CB}$ and $\mathrm{CR}$ in the Gymnophionan Brain tempts to clarify the amphibian condition of a given system must include results not only of anurans and urodeles but also of gymnophionans.

Immunohistochemical detection of calcium-binding proteins (CBPs) in the brain has been demonstrated to be a useful tool for distinguishing subpopulations of neurons. Among the CBPs, calbindin-D28k (CB) and calretinin (CR) abundantly occur in various types of neurons in the central nervous system of mammals [García-Segura et al., 1984; Fournet et al., 1986; Jones and Hendry, 1989; Celio, 1990; Jacobowitz and Winsky, 1991; Baimbridge et al., 1992; Résibois and Rogers, 1992; Rogers and Résibois, 1992; Winsky et al., 1992; Andressen et al., 1993; Arai et al., 1994; De Biasi et al., 1994; Molinari et al., 1994; Gutiérrez et al., 1995]. These proteins act as fast calcium buffers and actively operate in calcium-mediated signal transduction [Heizmann and Braun, 1992; Polans et al., 1996]. However, the dissimilarities in CB and CR sequence [Parmentier, 1990] reflect functional and evolutionary differences between the two proteins in terms of adaptation to different targets [Schwaller et al., 2002; Palczewska et al., 2003]. CR is considered a pure $\mathrm{Ca}^{2+}$ buffer which acts as passive modulator of the cytosolic calcium levels [Schmidt et al., 2007], whereas CB acts as a sensor that regulates the degradation of inositol messengers in an activity-dependent manner [Schmidt et al., 2005] and has a neuroprotective capability to prevent degeneration [Wang et al., 2008]. Thus, each protein seems to play specific roles in different neuron subsets. Moreover, the frequent use of CBPs in anatomical studies is mainly based on their occurrence in defined neuronal classes and, within the cell, usually throughout the whole cytoplasm including that of fine processes, which results in Golgi-like staining by immunohistochemistry. In addition, similar studies in nonmammalian vertebrates corroborated that the localization of CB and CR is extremely useful for identifying nuclear boundaries that are difficult to distinguish based on cytoarchitectonic criteria alone [Lunam, 1989; Rodríguez-Moldes et al., 1990a, b; Pombal and Puelles, 1999; Dávila et al., 2000; Díaz-Regueira and Anadón, 2000; Huesa et al., 2006; Morona et al., 2006a, b, 2007a].

Previous studies in anurans and urodeles demonstrated that CB and CR are powerful markers of well-segregated positive neuronal populations, fiber tracts, and neuropils in the brains of amphibians [Milán and Puelles, 2000; Morona and González, 2008, 2009]. Moreover, the patterns observed were consistent with the conceptual subdivision entities contemplated in the segmental paradigm of the brain, and the analysis of the results attending to this paradigm highlighted comparisons across spe- 
cies of different vertebrate classes [Pombal and Puelles, 1999; Dávila et al., 2000; González et al., 2002; Puelles and Rubenstein, 2003; Morona and González, 2008, 2009]. Our main aim in the present study was to provide a comprehensive description of the distribution patterns of neurons and fibers which are CB and CR immunoreactive (CBir and CRir, respectively) throughout the full extent of the brain of one gymnophionan amphibian, Dermophis mexicanus, with a view to identifying subpopulations of neurons not distinguished on the basis of cytoarchitecture alone. This study, in comparison with previous studies in anurans and urodeles [Milán and Puelles, 2000; Morona and González, 2008, 2009], will help to gain a better understanding of the anatomical complexity of the amphibian brain. The current neuromeric models [Gilland and Baker, 1993; Marín and Puelles, 1995; Fritzsch, 1998; Cambronero and Puelles, 2000; Díaz et al., 2000; Puelles and Rubenstein, 2003; Straka et al., 2006] are used as a framework for the interpretation of the results, thus allowing a ready comparison among amphibians and other vertebrates.

\section{Materials and Methods}

\section{Animals and Tissue Processing}

For the present study, 6 specimens of the gymnophionan $D$. mexicanus were used. Three adults (body length about $50 \mathrm{~cm}$ ) were males and 1 was a female (about the same size), but the other 2 brains corresponded to adult specimens whose sex was not determined. The animals were adults obtained from authorized commercial suppliers (Triton Madrid, Spain). They were kept in a room with a controlled temperature $\left(25^{\circ} \mathrm{C}\right)$ and natural light/dark conditions for a few days before being used. The original research reported herein was performed according to the regulations and laws of the European Union (86/609/EEC) and Spain (Royal Decree 1201/2005) for the care and handling of animals in research.

The animals were anesthetized in a $0.3 \%$ solution of tricaine methanesulfonate (MS222, pH 7.4; Sigma, St. Louis, Mo., USA) and perfused transcardially with saline followed by $200 \mathrm{ml}$ of $4 \%$ paraformaldehyde in $0.1 \mathrm{M}$ phosphate buffer (PB; $\mathrm{pH}$ 7.4). The brains were removed and kept in the same fixative for $2-3 \mathrm{~h}$. Subsequently, they were immersed in a solution of $30 \%$ sucrose in $\mathrm{PB}$ for $5 \mathrm{~h}$ at $4{ }^{\circ} \mathrm{C}$ until they sank, embedded in a solution of $20 \%$ gelatin with $30 \%$ sucrose in $\mathrm{PB}$, and then immersed in a $3.7 \%$ formaldehyde solution at $4{ }^{\circ} \mathrm{C}$ for $8-10 \mathrm{~h}$. The brains were cut on a freezing microtome at $40 \mu \mathrm{m}$ in the transverse or sagittal plane and collected in cold PB.

\section{$C B$ and $C R$ Immunohistochemistry}

The free-floating sections were rinsed twice in $\mathrm{PB}$, treated with $1 \% \mathrm{H}_{2} \mathrm{O}_{2}$ in $\mathrm{PB}$ for $15 \mathrm{~min}$ to reduce endogenous peroxidase activity, rinsed again 3 times in $\mathrm{PB}$, and processed via the peroxidase antiperoxidase method [Sternberger, 1979]. This included a first incubation of the sections in a mouse anti-CB or rabbit
anti-CR serum (catalog No. 300 and 7699/4, respectively; Swant, Bellinzona, Switzerland), diluted 1:1,000 in PB containing 0.5\% Triton X-100 (PBS-T), for $48-72 \mathrm{~h}$ at $4^{\circ} \mathrm{C}$. Subsequently, they were rinsed in $\mathrm{PB}$ for $10 \mathrm{~min}$ and incubated in the secondary antiserum goat anti-mouse (diluted 1:50 in PBS-T; Dako, Glostrup, Denmark) or swine anti-rabbit (diluted 1:50 in PBS-T; Dako) for 60 $\mathrm{min}$ at room temperature. After rinsing, the sections were incubated for $90 \mathrm{~min}$ in either mouse or rabbit peroxidase antiperoxidase complex (diluted 1:500 in PBS-T; Dako) and rinsed 3 times in PB. Finally, the sections were stained in $0.5 \mathrm{mg} / \mathrm{ml} \mathrm{3,3' \textrm {di } -}$ aminobenzidine (DAB; Sigma) or in DAB intensified with nickel [Adams, 1981] with $0.01 \% \mathrm{H}_{2} \mathrm{O}_{2}$ in $\mathrm{PB}$ for $10-20 \mathrm{~min}$. Some series of sections were stained according to the glucose oxidase method [Shu et al., 1988], which enhances the staining of fibers and terminals. The sections were then mounted on glass slides from a solution of $0.25 \%$ gelatin in $0.05 \mathrm{M}$ Tris- $\mathrm{HCl}$ buffer ( $\mathrm{pH} 7.6)$, and after dehydration the slides were coverslipped with Entellan (Merck, Darmstadt, Germany). Some sections were counterstained with cresyl violet to facilitate analysis of the results.

\section{Double Immunohistofluorescence}

To study the colocalization/codistribution of $\mathrm{CB}$ and $\mathrm{CR}$, a 2-step protocol for immunohistofluorescence was used with antibody cocktails as follows: (1) incubation for $72 \mathrm{~h}$ at $4^{\circ} \mathrm{C}$ in a mixture of primary mouse anti- $\mathrm{CB}$ antibody and rabbit anti-CR antiserum (both diluted 1:1,000 in PBS-T) and (2) a second incubation for $90 \mathrm{~min}$ at room temperature in a mixture of Alexa 488-conjugated goat anti-mouse (green fluorescence, diluted 1:300 in PBS-T; Molecular Probes, Eugene, Oreg., USA) and Alexa 594-conjugated goat anti-rabbit (red fluorescence, diluted 1:500 in PBS-T; Molecular Probes). After rinsing, the sections were mounted on glass slides and coverslipped with Vectashield (Vector, Burlingame, Calif., USA).

\section{Controls and Specificity of the Antibodies}

Prior to all incubations in the second antibody cocktails, the sections were incubated for $1 \mathrm{~h}$ at room temperature in normal serum of the species in which the secondary antibodies were obtained. Immunohistochemical control experiments involved parallel incubation of alternate sections with antiserum raised against different antigens, with normal serum, or with the omission of primary antiserum. No residual immunostaining was detected.

The specificity of the antibodies used against $\mathrm{CB}$ and $\mathrm{CR}$ was assessed by the commercial company (Swant). The monoclonal antibody anti-CB used in this study is a mouse IgG produced by hybridization of mouse myeloma cells with spleen cells from mice immunized with $\mathrm{CB}$ purified from chicken gut. Although the actual CB molecule in Dermophis has not been characterized, the calb-1 gene coding this protein in Xenopus (gene ID 399307) is highly conserved in humans, chimpanzees, dogs, cows, mice rats, chickens, and zebrafish. The sequence of Xenopus shows $97 \%$ similarity with that of the chick and includes the EF domain. Furthermore, the anti-CB used has been tested via Western blot with brain extracts of several species of amphibians and labeled a single band of the expected molecular weight $(28 \mathrm{kDa})$ that corresponds well with a similar band labeled in the lane of rat brain extract [Morona and González, 2008]. Additionally, because CB is highly homologous to CR ( $60 \%$ of coincidence in the primary amino acid sequence) [Rogers, 1987], we evaluated the lack of cross-reactivity 


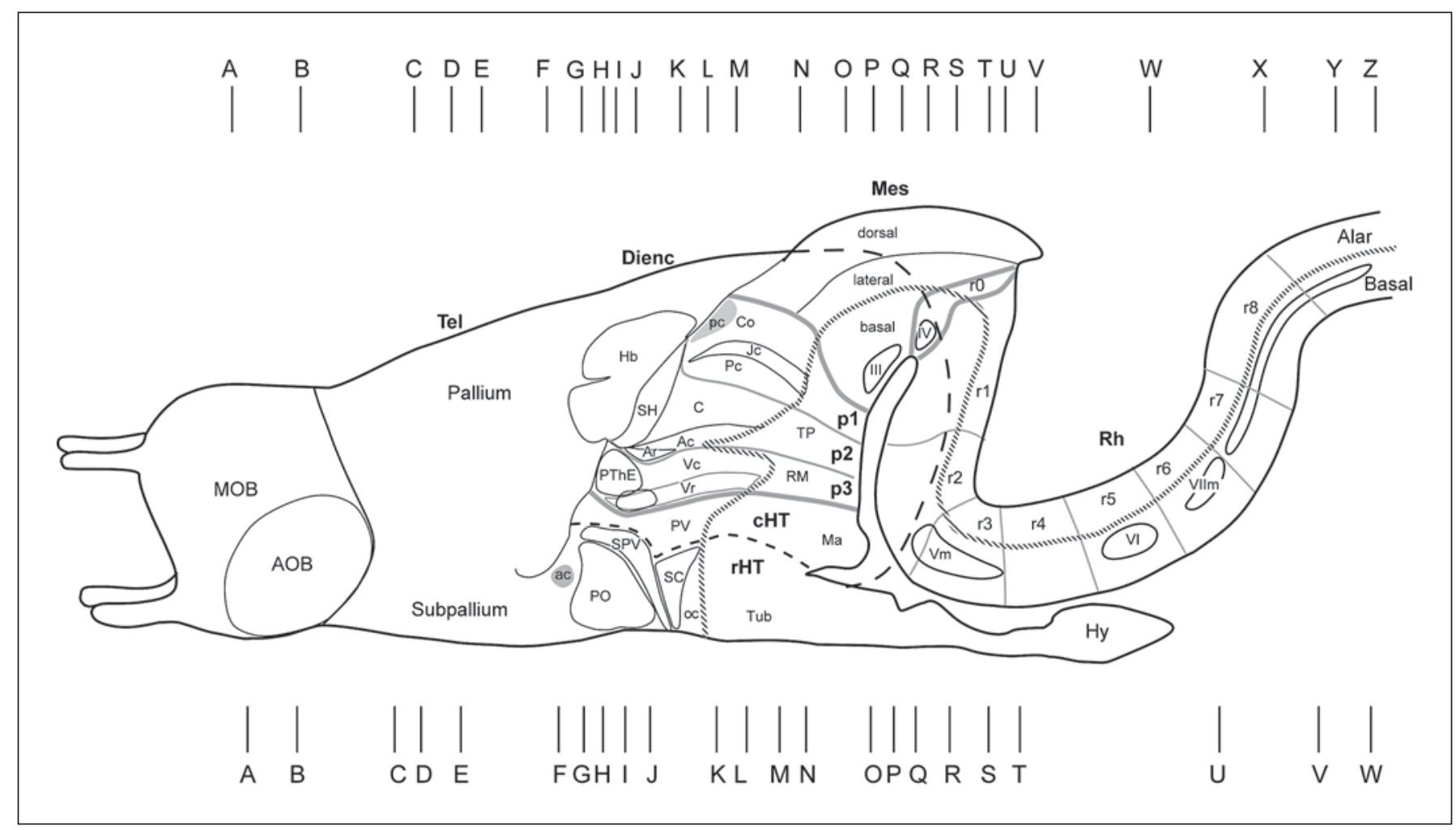

Fig. 1. Scheme of a lateral view of the brain of D. mexicanus in which the revised and simplified prosomeric model has been adapted [Puelles and Rubenstein, 2003]. There are 3 segments in the diencephalon, i.e. prosomeres $1-3$. The rostralmost forebrain contains the basal and alar parts of the hypothalamus. Following this model, the hypothalamus is divided into rostral and caudal transverse subdomains. It has also been subdivided into separate areas in the alar and basal parts: the preoptic (PO), SPV, suprachi- asmatic (SC), paraventricular (PV), tuberal (Tub), and mammillary $(\mathrm{Ma})$ regions. The telencephalon represents an extension of the alar hypothalamic region and is further subdivided into the pallium and subpallium. The segmentation of the brainstem follows that described previously [González et al., 2002a]. The a-z and $\mathrm{a}-\mathrm{w}$ levels of the sections shown in figures 2 and 3 are indicated. by means of control experiments [Morona et al., 2006a, b, 2007a, b] in which sections were incubated in the anti-CB serum preabsorbed at $4^{\circ} \mathrm{C}$ overnight with CR protein $(1 \mu \mathrm{g} / 1 \mathrm{ml}$ of the diluted antibody; Swant). Control sections were then processed in the same manner as those incubated with the unabsorbed antisera. As a result, no difference in the staining pattern of the antibody was observed, except for the overall staining, which was weaker than under normal conditions. The lack of cross-reactivity between the $\mathrm{CB}$ and the $\mathrm{CR}$ antibodies or antiserum in the present study was clear in that many cells were distinctly stained for either $\mathrm{CB}$ or CR and only a small portion of neurons was doubly labeled in the combined experiments.

The antiserum against CR was produced in rabbits by immunization with recombinant human CR. Its specificity has been demonstrated for many vertebrate species, and it does not crossreact with $\mathrm{CB}$. The $\mathrm{CR}$ protein in amphibians (predicted from locus XP 002931730 in Xenopus) has $82 \%$ similarity with the human CR. In Dermophis, anti-CR was preabsorbed with $1 \mu \mathrm{g} / \mathrm{ml}$ antigen isolated from rat brain at $4^{\circ} \mathrm{C}$ overnight, after which immunostaining was completely abolished. At the same time, pre- absorption of the anti-CR antibody under the same conditions with $100 \mu \mathrm{g} / \mathrm{ml} \mathrm{CB}$ (from chicken gut) did not affect staining. Furthermore, the primary antibodies used in our study have previously been employed in numerous amphibian species [Gábriel et al., 1998; Marín et al., 1998; Necchi et al., 1999; Uray and Gona, 1999; Edmonds et al., 2000; Milán and Puelles, 2000; Brox et al., 2003; Morona and González, 2008, 2009]. The same anti-CR has been tested via Western blot with brain extracts of several species of amphibians and labeled a single band of the expected molecular weight $(29 \mathrm{kDa})$ that corresponds well with a similar band labeled in the lane of rat brain extract [Morona and González, 2008].

\section{Evaluation and Presentation of the Results}

The localization of CBir and CRir cell bodies and fibers was studied throughout the brain in both the single-labeled sections and the double-labeled sections. Their relative localization was framed within the newly defined territories in the amphibian telencephalon and the segmental model proposed for the caudal prosencephalon and brainstem (fig. 1) recently adapted for anurans 


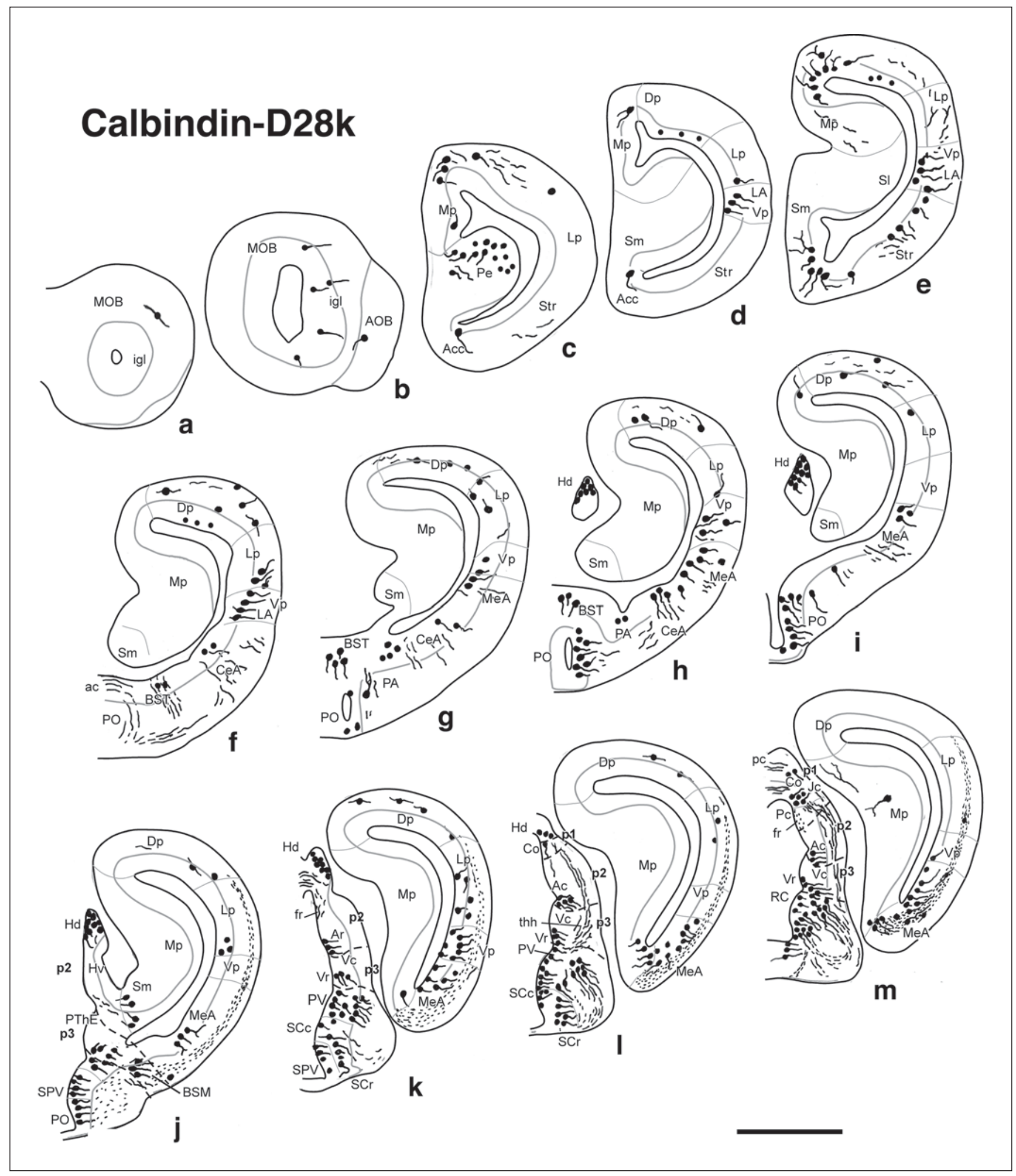

Fig. 2. Diagrams of transverse sections of the brain of D. mexicanus (at the rostrocaudal levels indicated in fig. 1) showing the distribution of CBir cell bodies (large dots) and fibers (small dots, wavy lines) in the right half of each section. Scale bar $=1,000 \mu \mathrm{m}$. 


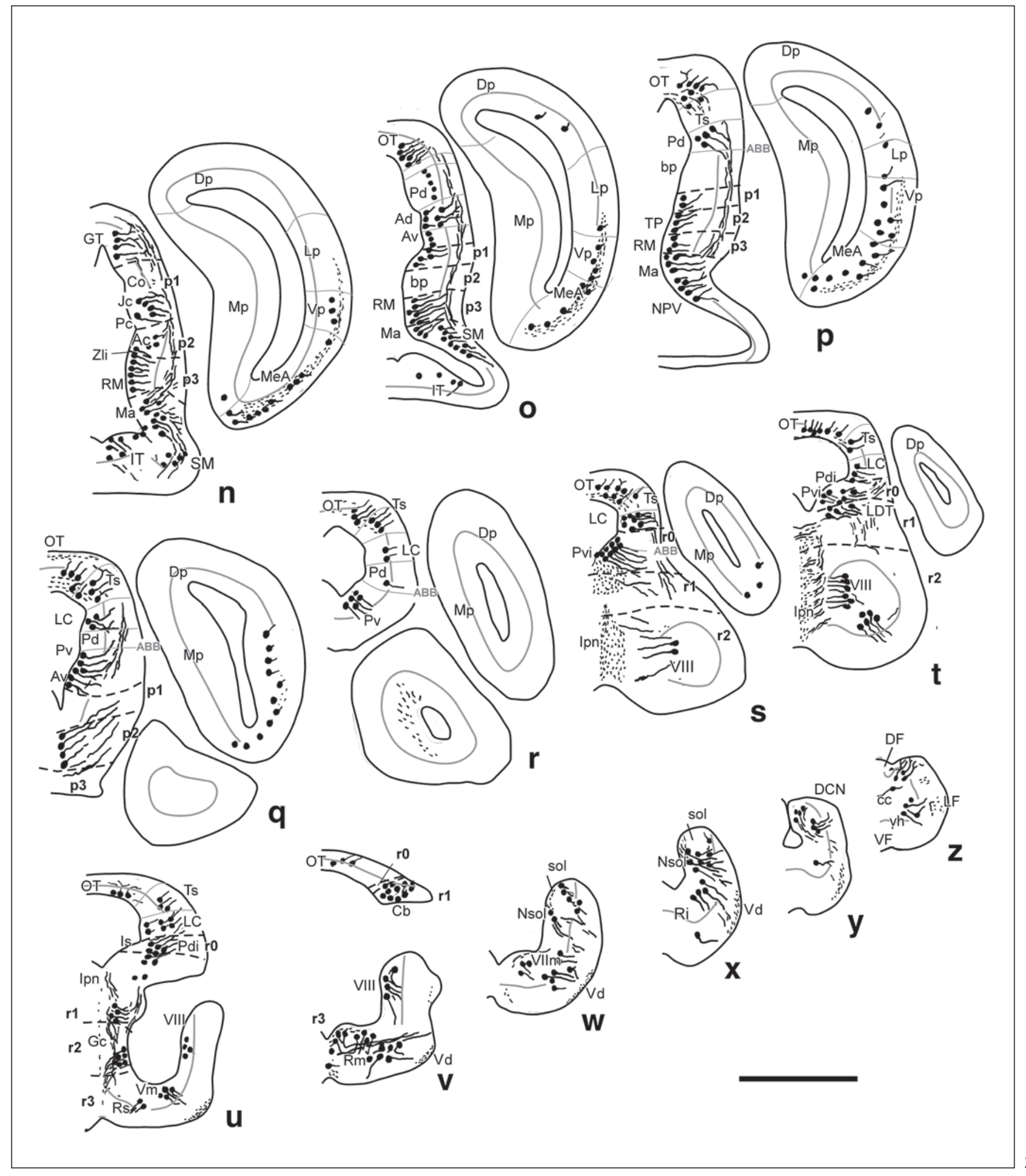




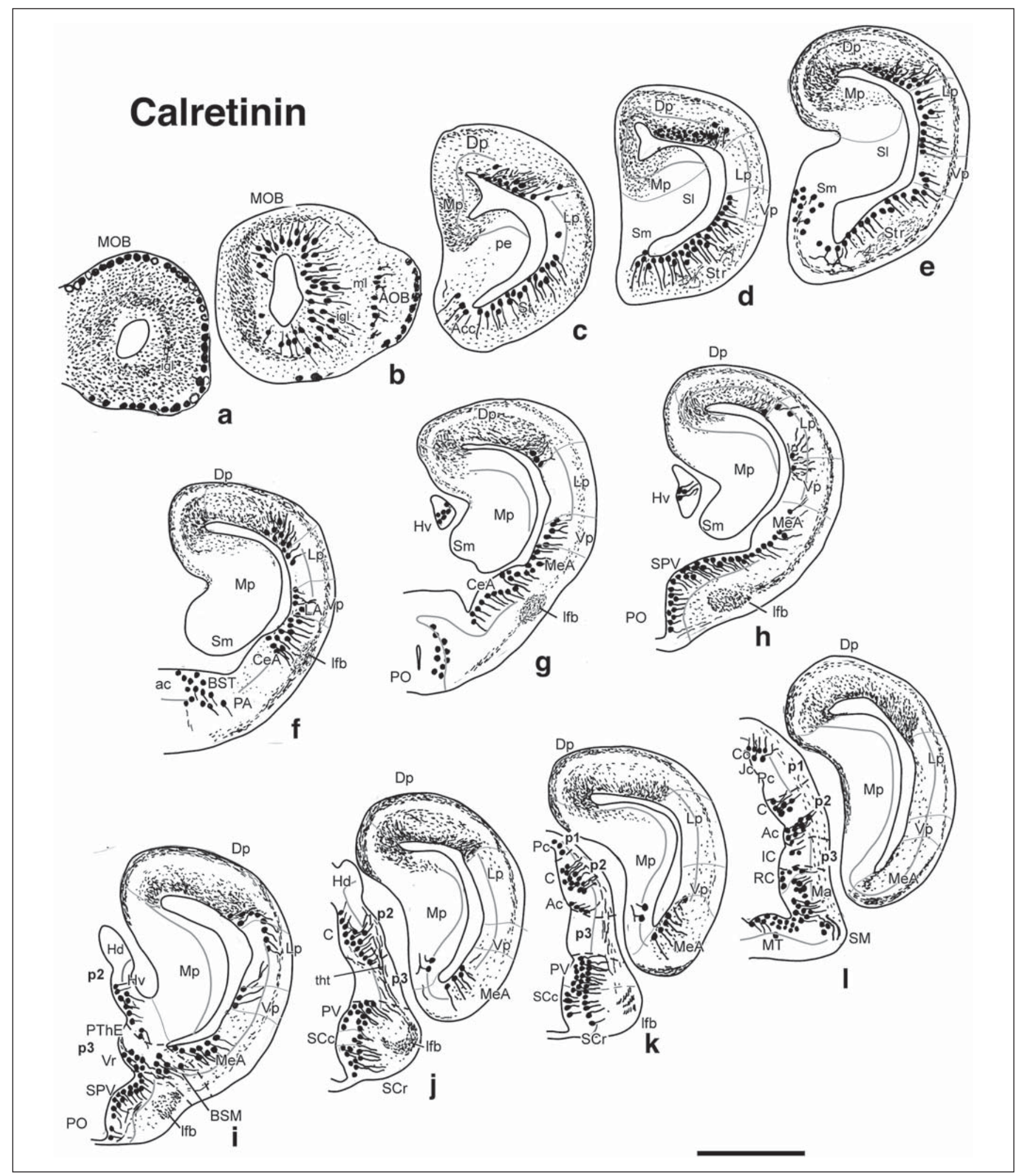

Fig. 3. Diagrams of transverse sections of the brain of D. mexicanus (at the rostrocaudal levels indicated in fig. 1) showing the distribution of CRir cell bodies (large dots) and fibers (small dots, wavy lines) in the right half of each section. Scale bar $=1,000 \mu \mathrm{m}$. 


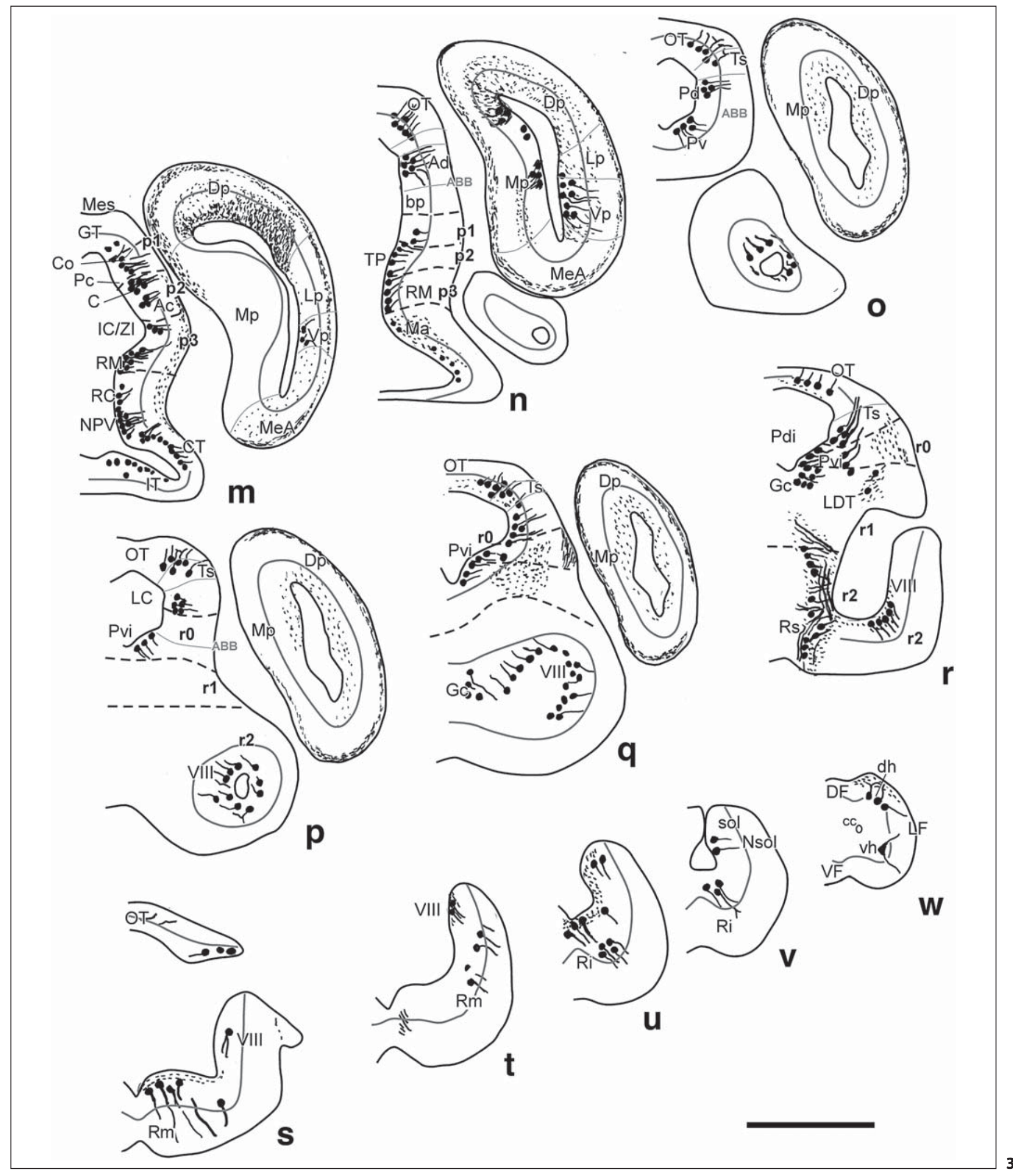


and urodeles [Morona and González, 2008, 2009]. The distribution of CB- and CR-labeled structures was charted by means of a camera lucida in a series of transverse sections from rostral to caudal (fig. 2,3). The chartings are meant to indicate the relative positions and densities of immunolabeled structures in the brain. Selected single-labeled transverse (fig. 4-7) or sagittal (fig. 8, 9) sections were photographed with a digital camera (Coolpix 930; Nikon). The double-labeled sections were analyzed with an Olympus BX51 microscope equipped for fluorescence with appropriate filter combinations, and selected sections were photographed (fig. 10) with a digital camera (Olympus DP70). In all cases, the contrast and brightness of the photomicrographs were adjusted using Adobe Photoshop 7.0 (Adobe Systems, San Jose, Calif., USA).

The nomenclature used largely follows that established in similar studies of the anuran and urodeles brains [Milán and Puelles, 2000; Morona and González, 2008, 2009].

\section{Results}

The antibodies against $\mathrm{CB}$ and $\mathrm{CR}$ used in the present study labeled cell bodies and fibers throughout the brain and spinal cord of Dermophis. They revealed distinct patterns of immunohistochemistry for each protein that were constant from animal to animal, and no differences were noted that could suggest sex differences. Mostly segregated patterns for $\mathrm{CB}$ and $\mathrm{CR}$ were obtained and only in some areas was colocalization of both proteins in some neurons detected by the double-immunohistofluorescence technique.

We describe the distribution of CBir and CRir cells and fibers following the main brain subdivisions from rostral to caudal (fig. 1). The analysis is mainly made on the basis of transverse sections that can be followed in the schemes (fig. 2,3) and selected sets of microphotographs (fig. 4-7). However, a specific feature of the gymnophionan brain, not observed in anurans and urodeles, is a pronounced flexure of the longitudinal axis at mesencephalic levels that bends the brainstem in such a manner that the upper rhombencephalon is placed beneath the mesencephalon (see scheme in fig. 1). Thus, conventional 'transverse' sections through the diencephalon and rostral brainstem are almost horizontal sections (parallel to the alar/basal boundary). For this reason, the analysis of sagittal sections has been most valuable for identifying the correct position of labeled cell groups and the course of fiber tracts (fig. 8, 9).

We here analyze the distribution of $\mathrm{CB}$ and $\mathrm{CR}$ using as a framework the distinct components of the telencephalon recently identified in anurans and urodeles, the prosomeric model for the diencephalon and nontelencephalic secondary prosencephalon [Puelles et al., 1996; Milán and Puelles, 2000; Puelles and Rubenstein, 2003], and the neuromeric organization of the brainstem [Straka et al., 1998; Díaz et al., 2000; Straka et al., 2006]. This has been accomplished by direct comparison with the results obtained in anurans and urodeles using the same immunohistochemical techniques [Morona and González, 2008, 2009].

\section{Olfactory Bulbs}

The main olfactory bulbs (MOB) of Dermophis are large structures formed in the rostral hemispheres, and conspicuous accessory olfactory bulbs (AOB) are located ventrolaterally to the main bulbs (fig. 1). Both bulbs consist of concentric layers with the incoming olfactory and vomeronasal fibers forming glomeruli in the most superficial layer. In centripetal order, interior to the glomerular layer is the external cellular layer that contains the mitral cells, the extragranular plexiform layer composed of secondary olfactory fibers, the thick internal granular layer, and the ependyma [Northcutt and Kicliter, 1980]. Within the bulbs, CB was only located in scattered cells distributed in the internal granular layer of the MOB and, to a lesser extent, the AOB (fig. 2a, b). In contrast, abundant CRir cells and fibers occupied the olfactory bulbs (fig. 3a, b, $4 a, b)$. An intricate network of labeled fine fibers were localized in practically all layers of the MOB and AOB. The primary olfactory and vomeronasal fibers and the glomeruli that they form in the periphery of the bulbs were intensely CRir. No labeled cells were observed in the periglomerular position. Most CRir cells were found in the internal granular layer of the $\mathrm{MOB}$ and $\mathrm{AOB}$ and, in the former, those located more peripherally showed a slightly larger size (fig. 4b). Just caudal to the MOB, adjacent to the rostral tip of the medial pallium, a region iden-

Fig. 4. Photomicrographs of singly stained transverse sections showing CBir and CRir cells and fibers (indicated in each photograph) in prosencephalic areas of D. mexicanus. a AOB. b MOB. c Detail of CBir cells in the postolfactory eminence. d, e Detail of $\mathrm{CB}$ and $\mathrm{CR}$ distribution in the dorsal pallium at comparable levels in the rostral telencephalic hemisphere. $\mathbf{f}$ CRir cells and fibers in the rostral striatum. $\mathbf{g}$ Detail of the caudal CBir cells in the medial amygdala. $\mathbf{h}$ CR immunoreactivity in the caudal telencephalic areas, just rostral to the anterior commissure. $\mathbf{i}, \mathbf{j}$ CBir and CRir cells and fibers in diencephalic and hypothalamic areas at comparable levels. $\mathbf{k}$, I Detail of CBir cells in the mammillary region and CRir cells in the tuberal region, respectively. $\mathbf{m}$ CBir cells and fibers in the dorsal nucleus of the habenula. $\mathbf{n}$ CRir cells and fibers in the ventral habenular nucleus. o CRir cells at caudal diencephalic levels in the pretectal and thalamic regions. Scale bars = $100(\mathbf{a}-\mathbf{j}, \mathbf{m}-\mathbf{o})$ and $50 \mu \mathrm{m}(\mathbf{k}, \mathbf{l})$. 

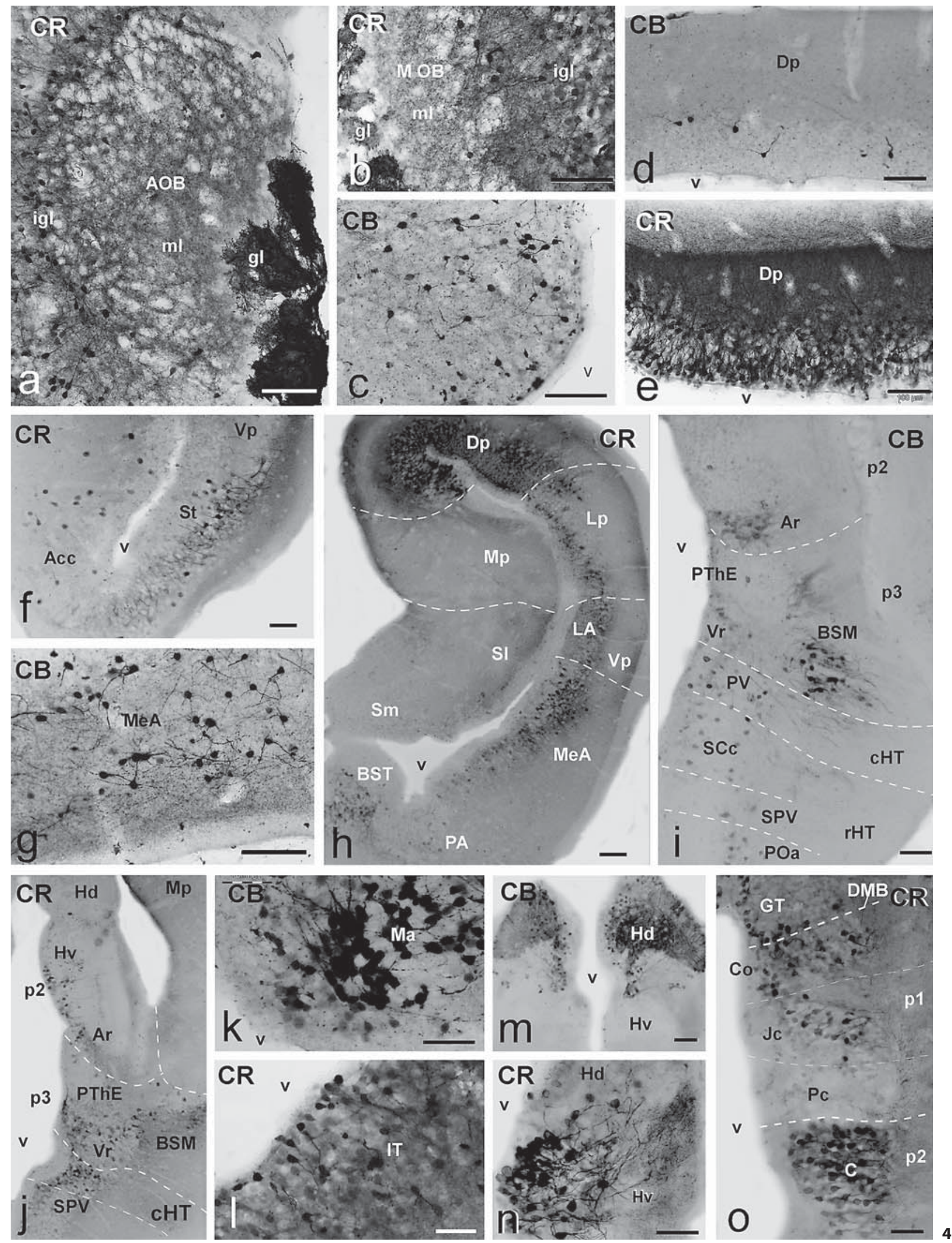


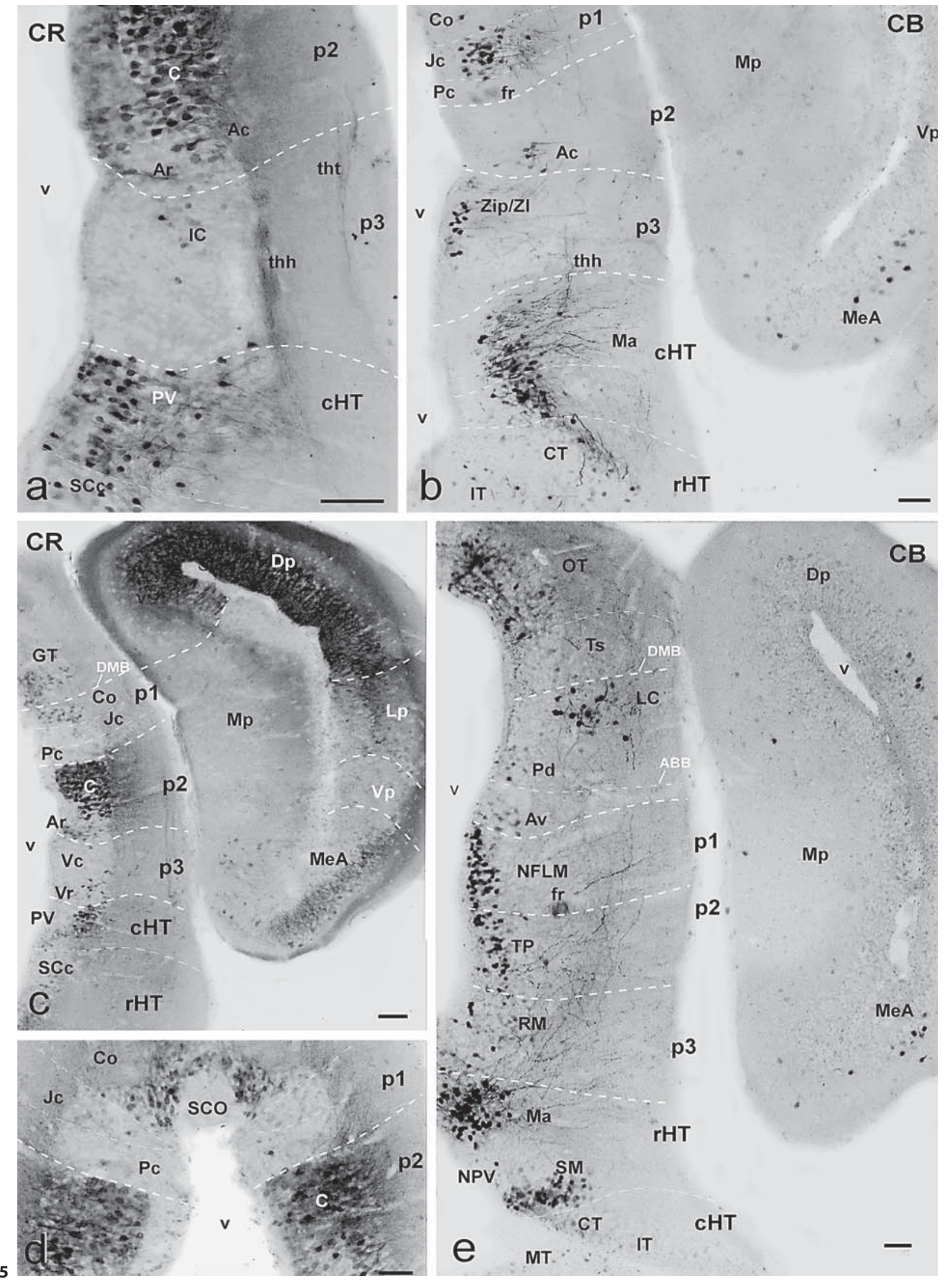


tified as the postolfactory eminence [Northcutt and Kicliter, 1980] contained a relative large number of CBir small cells (fig. 2c, 4c, 8c, d) and only labeled fibers for CR (fig. 3c, 9c).

\section{Pallium}

A peculiarity of the brain of gymnophionans, and not only of Dermophis, is the enormous development of the telencephalic hemispheres and, in particular, the extent of the pallium that is caudally enlarged, laterally covering the diencephalon and the upper brainstem (fig. 2c-t, 3cq, 8, 9) [Zilles et al., 1981]. The presence of CBir elements in the pallium was observed only in a small population of cells that were concentrated mainly in the medial part of the dorsal pallium and the rostral portion of the medial pallium (fig. $2 c-1,4 d, 8$ ). These cells were located in the deep cell layer, which is characteristic of the whole pallium of Dermophis, separated from the ventricular lining (fig. 4d). From mid to caudal telencephalic levels, the number of CBir cells was higher and occupied the ventral aspect of the lateral pallium, an area tentatively identified here as the ventral pallium (see Discussion) (fig. 2e-p). Strikingly different, the amount and intensity of CRir elements in the pallium were very conspicuous (fig. $3 \mathrm{c}-\mathrm{q}$, $4 \mathrm{e}, \mathrm{h}, 5 \mathrm{c}, 9)$. The pattern of CR labeling varied from rostral to caudal and from medial to lateral pallial regions. As in the case of $\mathrm{CB}$, the large medial pallium was practically devoid of CRir elements, whereas the adjacent dorsal pallium was intensely immunoreactive. At rostral levels of the hemispheres, the dorsal and lateral pallial regions showed a numerous population of intensely CRir cells located close to the ventricular lining and, within the outer thick fiber zone, the deep part was intensely CRir with fine fibers and terminal-like structures, whereas in the superficial part almost no labeling was observed (fig. 3c, d, 4e). In contrast, at caudal levels the superficial fiber zone that covers the dorsal pallium was filled with CRir fibers that formed a band that extended from the

Fig. 5. Photomicrographs of singly stained transverse sections showing CBir and CRir cells and fibers (indicated in each photograph) in diencephalic and hypothalamic areas of $D$. mexicanus. a CR-stained section through the diencephalon and hypothalamus highlighting the main prosomeric boundaries. $\mathbf{b} \mathrm{CB}$-stained section caudal to that shown in a. c CR immunoreactivity marks p2 and the dorsal pallium intensely in this section slightly rostral to that shown in $\mathbf{b}$. d Detail of CRir cells in pretectal and caudal thalamic areas. e Distribution of CBir cells and fibers in a classical 'transverse' section through mesencephalic areas, the basal diencephalon, and the hypothalamus. Scale bars $=100 \mu \mathrm{m}$.

$\mathrm{CB}$ and $\mathrm{CR}$ in the Gymnophionan Brain external dorsal part of the medial pallium through the dorsal pallium and dispersed in the deep aspect of the lateral and ventral pallial regions and entered the amygdaloid zones (fig. $3 \mathrm{e}-1,4 \mathrm{~h}, 5 \mathrm{c}$ ). Similar to the case of CB, abundant CRir neurons were located in the ventral pallium (described below in Amygdaloid Complex) (fig. 3e$1,4 h)$.

\section{Septum}

Gymnophionans possess a rostral septal area several times the size of the medial pallium, and its rostral tip has been compared with the previously described postolfactory eminence of anurans [Northcutt and Kicliter, 1980]. The septal enlargement at mid telencephalic levels, which has been considered the counterpart of the lateral septal nucleus of other amphibians, is located ventral to the medial pallium and both together form the thick medial wall of the hemisphere (fig. 2e, 3e, 4h). The septal bulge was devoid of CBir and CRir cells and only CRir fibers were located laterally in the septum, close the ventricle (fig. 4h). However, the septal portion that shows no particular enlargement and is located more ventrally has been compared to the medial septal nucleus of anurans and urodeles and showed a reduced population of CRir cells that were located close to the subpial surface (fig. 3e, 9d).

\section{Basal Ganglia}

By means of immunohistochemical detection of the dopaminergic innervation of the telencephalon, a striatum proper and a nucleus accumbens were identified as basal ganglia components in the subpallium of gymnophionans [González and Smeets, 1994; González et al., 1994]. The nucleus accumbens was localized at rostral telencephalic levels, ventral to the rostral septal region, and in the present study it was seen to contain only occasional CBir cell bodies and more abundant CRir neurons (fig. 2d, 3c, 4f). Also restricted was the distribution of CBir cells in the large striatum that occupies much of the ventrolateral wall of the hemispheres (fig. 2e). These cells showed pear-shaped somata with a main dendritic process directed toward the pial surface. The population of CRir neurons in the striatum of Dermophis was very large and extended the whole length of the striatal region (fig. $3 \mathrm{c}-\mathrm{e}, 4 \mathrm{f})$. The CRir cells were small neurons and showed dendritic processes mainly oriented ventrolaterally into the striatal neuropil where they arborized (fig. 4f). Most of the striatal neuropil was filled with CRir fibers and terminals that reached this region in the lateral forebrain bundle from diencephalic territories (fig. 3e-k). In Dermophis, no pallidal structures have been previously de- 


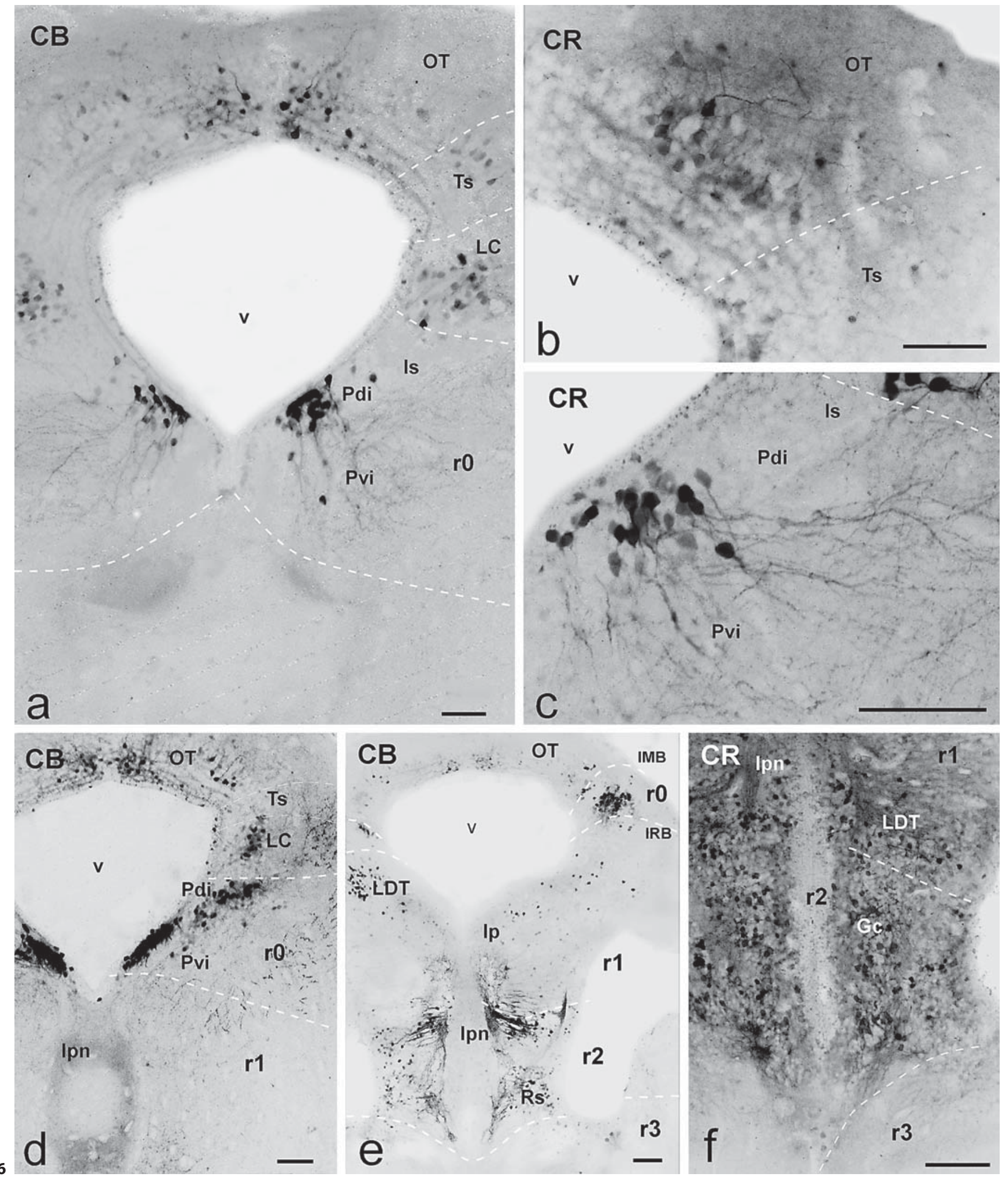


scribed. Recently, in urodeles, a pallidal portion in the ventrocaudal telencephalon has been demonstrated in the previously named ventral cellular prominence [Moreno and González, 2007a]. In our study, this area in Dermophis was located ventrally to the central amygdala (see below) and showed abundant intensely CBir cells (fig. $2 \mathrm{~g}$, h) and no CRir cells (fig. 3f, 4h).

\section{Amygdaloid Complex}

The amygdala of amphibians was traditionally subdivided into pars lateralis and pars medialis on the basis of topography [Northcutt and Kicliter, 1980]. However, research in the last years about the telencephalic organization in anurans and urodeles has proved that at least 3 main amygdaloid subdivisions can be considered that were named for facilitating their comparison with their counterparts in amniotes: lateral, central, and medial [Moreno and González, 2006, 2007a, b]. Several immunohistochemical studies in the brain of gymnophionans support the presence of the same subdivisions of the amygdaloid complex, and we have tentatively identified them in this study [González and Smeets, 1994; González et al., 2002a, b; López et al., 2006, 2007].

The amphibian lateral amygdala is considered a ventral pallial territory located between the lateral pallium (dorsally) and the striatum (ventrally) and is primarily identified by its content in nitrergic cells and fibers, its connections, and the expression of genetic markers [Moreno and González, 2004, 2006]. Within the putative lateral amygdala of Dermophis, a small population of CBir neurons was localized mainly at rostral telencephalic levels (fig. $2 \mathrm{~d}-\mathrm{h}$ ). Significantly more abundant were the CRir cells detected in the lateral amygdala that extended more caudally than the CBir cell population (fig. $3 \mathrm{~d}-\mathrm{i}$,

Fig. 6. Photomicrographs of singly stained transverse sections showing CBir and CRir cells and fibers (indicated in each photograph) in mesencephalic, isthmic, and rhombencephalic areas of D. mexicanus. a CBir cells are shown in the medial part of the OT, in the reduced torus semicircularis and the laterocaudal nucleus in the mesencephalon, and in the posterodorsal and posteroventral isthmic nuclei. b Detail of CRir cells at caudal levels in the OT. c Detail of CRir cells in the posteroventral isthmic nucleus. d Section immunoreacted for CB, caudal to that shown in a, that considering the brain flexure corresponds to more dorsal levels (see fig. 1) and shows the distinct labeling in the tectal and isthmic regions. e, $\mathbf{f}$ Transverse sections passing through the caudal mesencephalon and the upper rhombencephalon that correspond with actual horizontal sections and show the CBir cells and fibers (e) and a detail of the conspicuous CRir cell population in the Gc (f). Scale bars $=100 \mu \mathrm{m}$.

$\mathrm{CB}$ and $\mathrm{CR}$ in the Gymnophionan Brain 4h). The central amygdala of amphibians is currently interpreted as a caudal continuation of the striatum; both share the same origin in the developing lateral ganglionic eminence and are distinct in their hodology [Moreno and González, 2005]. In Dermophis, a similar territory occupies most of the previously named pars lateralis of the amygdala [Northcutt and Kicliter, 1980]. In this location, only scarce CBir cells were observed (fig. 2g, h), whereas a large population of CRir neurons formed a caudal continuation of the striatal cell population into the central amygdala (fig. 3f, g). The third component of the amygdaloid complex is the medial amygdala, which is primarily defined by its input from the AOB [Moreno and González, 2003, 2006, 2007a]. In Dermophis, this region would be included in the caudal portion of the former pars lateralis of the amygdala. Its rostral portion caps dorsally the central amygdala and extends caudally in the enlarged caudal pole of the hemispheres (fig. $2 g-p, 3 g-n$ ). Within the medial amygdala, CBir cells were always detected and were mainly located at its caudal levels (fig. 4g). However, the population of CRir neurons in the medial amygdala outnumbered that of CBir cells and was localized throughout the rostrocaudal extent (fig. 4h, 5c).

In relation to the amygdaloid complex of amphibians, a cell group located medial to the ventral tip of the lateral ventricle at caudal telencephalic levels has been proposed as the bed nucleus of the stria terminalis (BST) [Marín et al., 1998]. This region in anuran amphibians has been characterized by immunohistochemistry, development, and connectivity [Moreno and González, 2006; Moreno et al., 2011]. Its content of CB and CR has been analyzed [Morona and González, 2008] and by strict comparison a similar region has been considered in Dermophis. It was clearly occupied by CBir and CRir cells that formed a column that extended caudally to the anterior commissure (fig. 2g, h, 3f, 4h, 8a-d, 9a-c).

\section{Nontelencephalic Secondary Prosencephalon and Hypothalamus}

The set of structures comprised in this part of the brain is localized topologically rostral to the diencephalon (fig. 1). They include alar and basal plate derivatives defining rostral and caudal parts, whereas the aforesaid telencephalic territories consist only of alar derivatives [Puelles and Rubenstein, 2003]. The alar plate derivatives form a banded pattern of cells in the preoptic area, the supraoptoparaventricular band (SPV; containing the magnocellular neurosecretory nucleus) and the suprachiasmatic and paraventricular regions. Basal plate derivatives include the retrochiasmatic region, the tuberal (in-

Brain Behav Evol 2011;77:231-269 

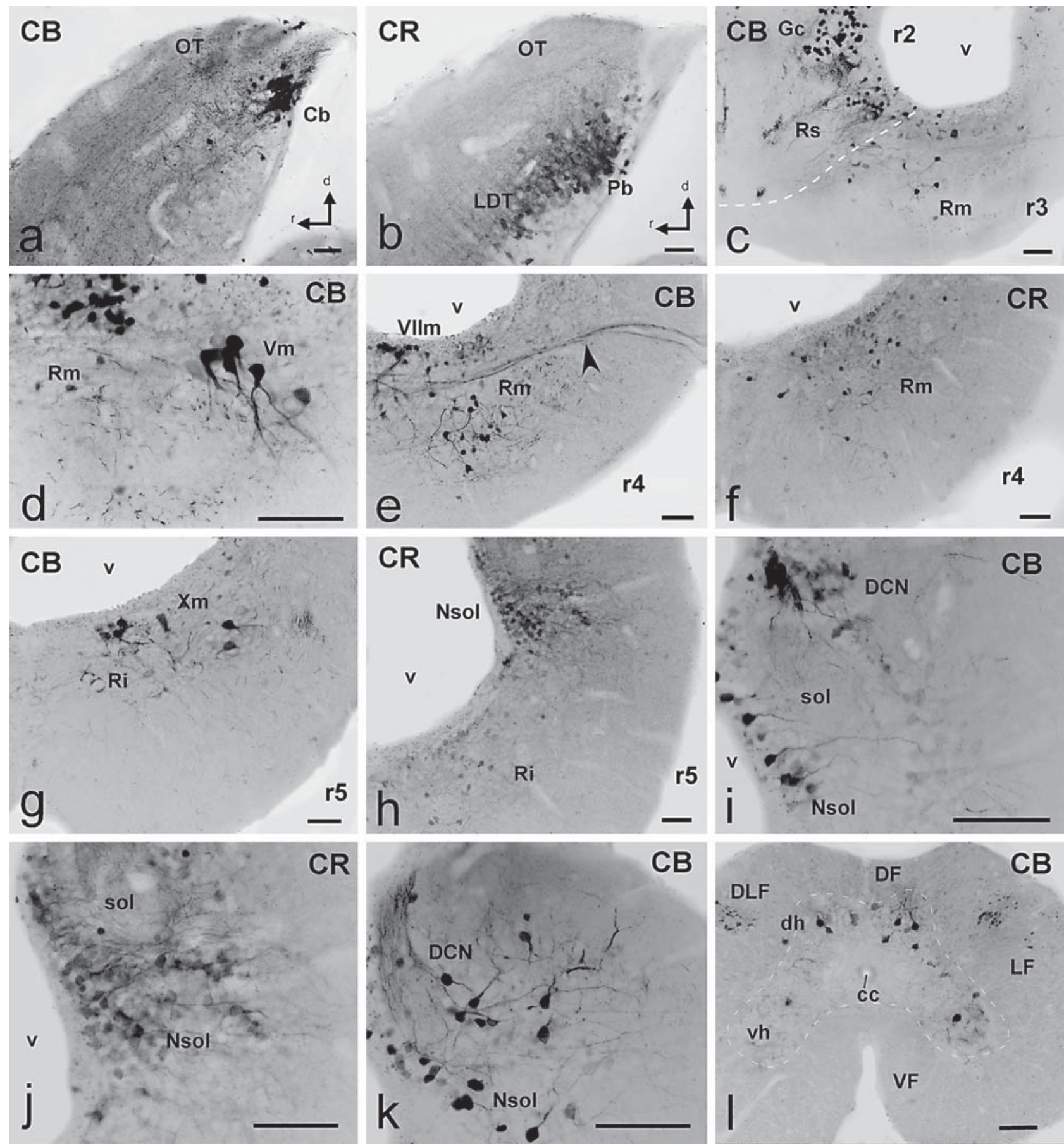

Fig. 7. Photomicrographs of singly stained sagittal (a, b) or transverse (c-I) sections showing CBir and CRir cells and fibers (indicated in each photograph) in the hindbrain of $D$. mexicanus. a, b Comparable sagittal sections showing the dorsal and lateral rim of the isthmo-mesencephalic boundary. $\mathrm{CB}$ intensely stained some cells in a complementary pattern to that of CR. c Distribution of numerous intensely CBir cells in the Gc and superior reticular nucleus in $\mathrm{r} 2$ and the reticular median nucleus in $\mathrm{r} 3$. $\mathbf{d}$ Detail of large CBir cells in the region of the trigeminal motor nucleus in $\mathrm{r}$. e, $\mathbf{f}$ Labeled reticular cells for each protein in $\mathrm{r} 4$ (arrowhead in $\mathbf{e}$ points to labeled fibers in the facial nerve). $\mathbf{g}$ Section at caudal levels of the rhombencephalon showing CBir in some large cells in the region of the vagal motor nucleus and in the inferior reticular nucleus. $\mathbf{h}$ CR staining in the basal reticular cells and in the alar group of the nucleus of the solitary tract. $\mathbf{i}, \mathbf{j}$ Detail of CBir and CRir cells in the caudal dorsal alar region showing distinct labeling in the nucleus of the solitary tract and the dorsal column nucleus. $\mathbf{k}$ Pattern of $\mathrm{CB}$ staining close to the obex in the nucleus of the solitary tract and the dorsal column nucleus. I Distribution of CBir cells in the first segments of the spinal cord. Scale bars $=100 \mu \mathrm{m}$. 
fundibular) hypothalamus (rostrally), and the mammillary region (caudally). Because of the already mentioned brain flexure, the 'transverse' sections through these regions are basically 'horizontal' sections (fig. 1). This scheme follows that proposed and analyzed for anurans [Puelles et al., 1996, Milán and Puelles, 2000] and extended for the case of urodeles [Morona and González, 2008]. Actually, in the brain of Dermophis the distribution of CB and CR helped the identification of these regions.

The localization of CBir cells included the preoptic area just beneath the anterior commissure and around the preoptic recess of the third ventricle (fig. $2 \mathrm{~g}-\mathrm{i}, 8 \mathrm{a}-\mathrm{d}$, 10a). They continued in the SPV and extended to regions adjacent to the medial amygdala (fig. $2 \mathrm{i}, \mathrm{j}, 4 \mathrm{i}, 8 \mathrm{~d}, 10 \mathrm{~d}$ ). Intense CBir neurons were observed in the suprachiasmatic region, primarily in the caudal part (fig. $2 \mathrm{k}, 1,4 \mathrm{i}, 8 \mathrm{c}$, d, 10d). A distinct population of CBir cells was also located in the paraventricular nucleus of the alar part of the caudal hypothalamus (fig. $2 \mathrm{k}, 1,4 \mathrm{i}, 8 \mathrm{a}, \mathrm{d}$ ). Within the basal part of the hypothalamus, the topologically rostral portion contained CBir cells in the retrochiasmatic region and the tuberal nuclei, mainly in the intermediate tuberal nucleus (fig. $2 \mathrm{~m}-\mathrm{o}$ ). In the caudal hypothalamus, the CBir cells located in the mammillary and superficial mammillary region were particularly abundant; their projections were observed to be directed toward the thalamus and the medial telencephalic wall, and they formed a cell population that continued caudally into the basal plate of the diencephalon (fig. $2 \mathrm{n}-\mathrm{p}, 4 \mathrm{k}, 5 \mathrm{~b}, \mathrm{e}, 8 \mathrm{a}-\mathrm{d}$ ).

With regard to the CRir cell populations, they were specially abundant in the anterior preoptic area and the SPV, which were dorsolaterally continued with the cells of the medial amygdala (fig. 3h, 9a-c). CRir were particularly abundant in the suprachiasmatic region (fig. 3j, k) and mainly occupied a peripheral position in the periventricular cell layer (fig. 5a, c, 10d). A striking group of CRir cells was found in the paraventricular nucleus of the alar caudal hypothalamus that limited with the caudal diencephalon that was almost devoid of labeling (fig. 3j, k, 5a). Within the basal hypothalamus, CRir cells were conspicuous in the tuberal region in which the medial, intermediate, and caudal nuclei showed intensely labeled cells (fig. 3l, m, 4l, 9a-d). Caudally, CRir neurons were present in the mammillary band (fig. 9a-d), mainly forming a strip of cells in the named superficial mammillary nucleus, located laterally to the nucleus of the periventricular organ (fig. $3 \mathrm{~m}$ ). It is important to note that the optic chiasm is rudimentary in Dermophis and the optic tracts are very reduced and were not labeled for $\mathrm{CB}$ or $\mathrm{CR}$.

\section{Diencephalon}

This portion of the gymnophionan brain, as mentioned above, is almost vertically oriented due to the sharp flexure of the brain (fig. 1). Thus, the 3 neuromeres that constitute the diencephalon (p1-p3) in conventional transverse sections appear one above the other. Sagittal sections are better suited for understanding the actual neuromeric arrangement of the diencephalic cell groups in Dermophis (fig. 8, 9). In fact, CB and CR immunohistochemistry has been especially useful for identification of the diencephalic neuromeres.

Within the rostral segment (p3), the prethalamic eminence occupies the dorsal position and it showed a CBir cell group identified as the bed nucleus of the stria medularis (BSM) by its relation with the fiber tract that crosses in the habenular commissure (fig. $2 \mathrm{j}, 4 \mathrm{i}, 8 \mathrm{~b}$ ). More ventrally, the prethalamus constitutes the alar part of $\mathrm{p} 3$ (previously named ventral thalamus) and in its rostral part (Vr) showed a group of CBir cells (fig. $2 \mathrm{k}-\mathrm{m}, 4 \mathrm{i}$ ), whereas CRir cells in Vr were located more medially and extended dorsally into regions medially situated to the BSM (fig. 3i, 4j). In clear contrast, the caudal part $(\mathrm{Vc})$ was almost totally devoid of labeled cells (fig. $2 \mathrm{k}-\mathrm{m}, 3 \mathrm{j}, \mathrm{k}, 8 \mathrm{c}$, d, 9b, d). Only at its most caudal levels was a band of CRir cells found in Vc that, by comparison with anurans and urodeles, was named an intercalated nucleus (IC in fig. 31, 5a, 9c). Abundant CBir cells occupied the basal part of $\mathrm{p} 3$ in the area generally identified as the retromammillary region (fig. $2 \mathrm{n}, \mathrm{o}, 5 \mathrm{e}, 8$ ). Within this region, a periventricular CBir cell group was very prominent and continued dorsally just between $\mathrm{p} 3$ and $\mathrm{p} 2$ in what has been termed the zona incerta by comparison with its content in dopaminergic cells [Milán and Puelles, 2000]. The CBir cells located ventrally in the basal plate formed a continuation with the cells in the mammillary region (fig. 8d). The basal plate of $\mathrm{p} 3$ also contained numerous CRir cells that were primarily located in the periventricular region (fig. $3 \mathrm{~m}, \mathrm{n}, 9 \mathrm{a}-\mathrm{d}$ ).

The intermediate diencephalic segment $\mathrm{p} 2$ contains dorsally the large habenulae and the thalamus (previously named dorsal thalamus), whereas the posterior tubercle is located in its basal plate (fig. 1). The dorsal p2 showed a strikingly complementary pattern of CB and CR immunoreactivity (fig. 10e). Thus, CBir cells and fibers conspicuously occupied the dorsal habenula (fig. $2 \mathrm{~h}-1,4 \mathrm{~m}$ ), whereas CRir cells and fibers were specifically distributed in the ventral habenula (fig. 3g, h, 4n). From the dorsal habenula, which forms a large protrusion that bends caudally on top of the dorsal part of p1, CB-labeled fibers coursed in the fasciculus retroflexus toward the ventral 

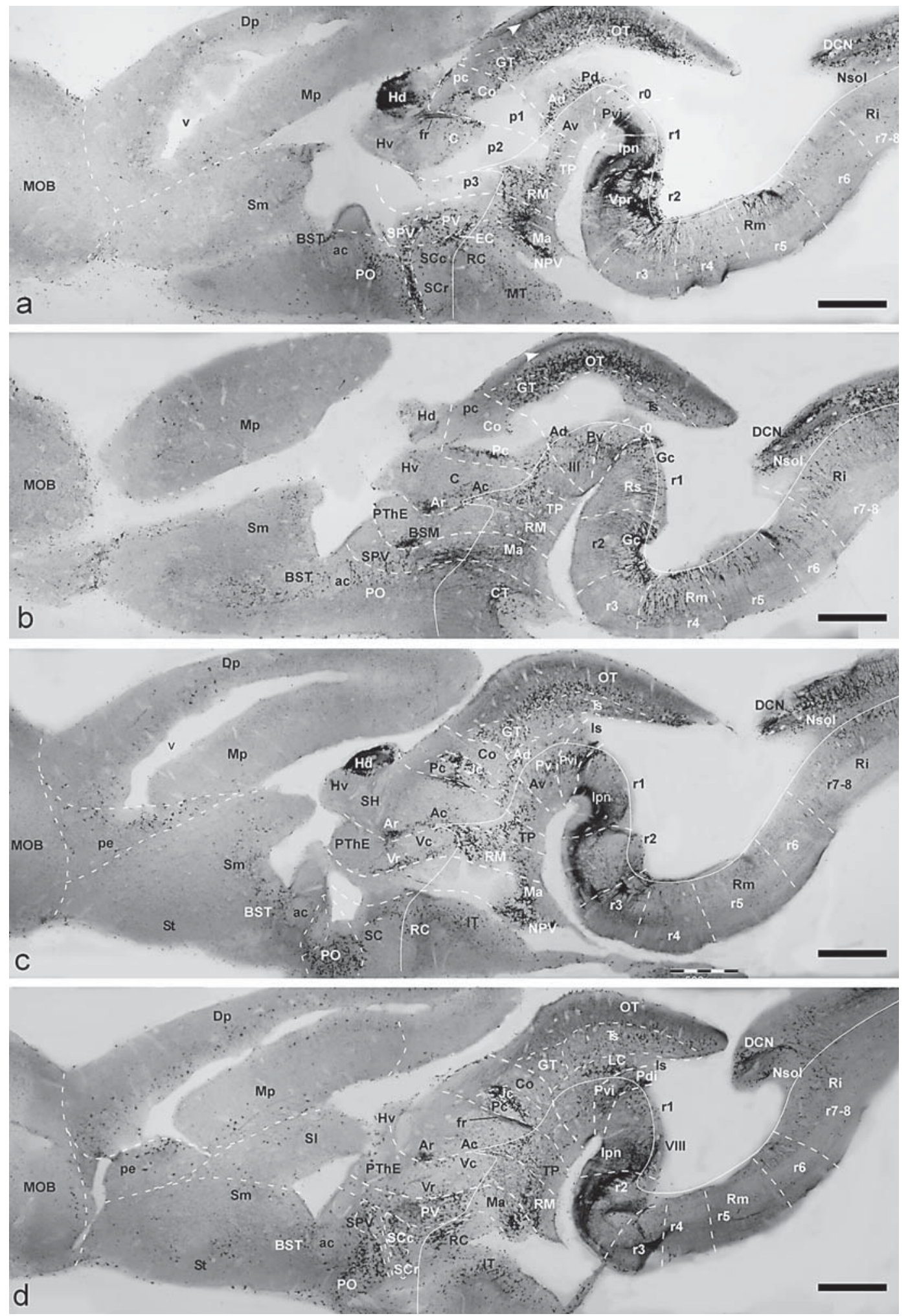

Fig. 8. Parasagittal sections showing CBir cells and fibers in the brain of D. mexicanus, presented in lateromedial order $(\mathbf{a}-\mathbf{d})$. Dorsal is oriented upward and rostral to the left. The diencephalic prosomeres p1-p3, the isthmus and rhombomeres are delimited by dash lines. The alar-basal boundary is indicated by a fine line. Scale bars $=1 \mathrm{~mm}$. 
tegmentum of the upper brainstem, with this tract serving as an indication for the boundary between $\mathrm{p} 2$ and $\mathrm{p} 1$ (fig. 5b, e, 8a, c, d). No asymmetry between right and left habenulae was noted in Dermophis on the basis of CB and CR labeling. CR immunohistochemistry was particularly suited for staining of the thalamus (fig. $3 \mathrm{j}-\mathrm{m}, 4 \mathrm{o}, 5 \mathrm{a}, \mathrm{c}, \mathrm{d}$, $9 \mathrm{a}, \mathrm{c}, \mathrm{d}, 10 \mathrm{f})$, whereas only subgroups of cells contained CB (fig. 2k-n, 4i, j, 5b, 10f). In keeping with the terminology used in anurans and urodeles, the rostral thalamic region is named the anterior (A) nucleus and the large caudal region is named the central $(\mathrm{C})$ nucleus. CBir cells were specifically located in A and formed a compact group rostrally (Ar) and a disperse group caudally (Ac). This caudal population overlapped with a larger population of CRir cells (fig. 10f). However, probably the most conspicuously stained brain region for $\mathrm{CR}$ was the central nucleus (fig. 4o, 5a, c, d. 9a-d, 10f). Between the CR-positive ventral habenula and the thalamus a nonstained territory was identified as the subhabenular region (fig. 8c, 9c). The intensely CR-labeled thalamic cells send their axons into the lateral forebrain bundle toward the subpallium, whereas axons from the thalamic CBir cells, and also CRir cells, organize a concise thalamohypothalamic tract (fig. 2l, 3j, 5a, b, 9d). In the basal plate of p2 (region of the posterior tubercle) CBir cells were more abundant than in the alar plate (fig. 2p, 5e). CRir cells were also numerous but more dispersely distributed than in the thalamus (fig. 3n, 9c, d) and occupied preferentially the periventricular zone, next to the CBir cells (compare fig. 2 p, $3 n)$.

The alar plate of the neuromere pl (pretectum) has been reinterpreted in amphibians and 3 main parts have been distinctly identified (as in amniotes): rostral precommissural ( $\mathrm{Pc}$ ), caudal commissural (Co), and intercalate juxtacommissural (Jc) parts [Morona et al., 2011]. This tripartite scheme could be identified in Dermophis on the basis of CB and CR distribution (fig. 1). A small group of intensely CBir cells was located close to the ventricle in the dorsal portion of the Pc (fig. 2n, 8b, 10f), whereas scattered CRir cells were found in this part (fig. $3 \mathrm{~m}, 4 \mathrm{o}$ ). Due to the restricted location of the labeled cells in the Pc, most transverse sections (actually oblique through p1) did not show immunoreactive cells in this part of the pretectum (fig. 5b-d). The Jc was particularly highlighted by a CBir cell population (fig. $2 \mathrm{~m}, \mathrm{n}, 8 \mathrm{c}$, d, $10 \mathrm{f}$ ), whereas CRir cells in this pretectal subdivision were more restricted (fig. 3l, 5c, 10g). Particularly Co, which occupies the whole length of the dorsal part of p1, contained a large population of small CRir neurons that helped to the identify its boundaries (fig. 4o, 5c, d, 9b, d).

\section{Mesencephalon}

This brain region in gymnophionans represents a narrow tube whose configuration is complicated by the pronounced ventral concavity of the longitudinal brain axis. Most of its cells are arranged as a more or less compact periventricular layer, and the distribution of $\mathrm{CB}$ and $\mathrm{CR}$ has been of great help in highlighting subdivisions. Rostrally, the diencephalomesencephalic boundary passes through the posterior commissure, whereas the transverse isthmo-mesencephalic limit passes behind the trochlear nucleus.

In our analysis, we considered the mesencephalon as a single brain segment that can be further subdivided into 4 longitudinal columns (bands), as previously proposed for amniotes [Díaz et al., 2000] and adapted for anuran and urodele amphibians [Morona and González, 2009]. Thus, the model identifies: (1) the dorsal band, which contains the optic tectum (OT) and 3 ventricular subdivisions named the griseum tectale (GT), the intermediate area, and torus semicircularis (Ts) in rostrocaudal order; (2) the lateral band, which forms the ventral margin of the alar plate and contains the anterodorsal (Ad), posterodorsal (Pd), laterorostral, and laterocaudal (LC) nuclei; (3) the basal band, which constitutes the basal plate or tegmentum proper and contains the anteroventral $(\mathrm{Av})$ and posteroventral $(\mathrm{Pv})$ nuclei, the red nucleus $(\mathrm{RN})$, and the oculomotor nucleus (III), and (4) the medial band, which contains the ventral tegmental area and represents the mesencephalic floor plate.

Rostrally in the mesencephalic dorsal band, the GT possessed numerous small round CBir cells in the ventricular and periventricular regions (fig. 2n, 8) and only some scattered CRir cells located more superficially (fig. $3 \mathrm{~m}, 9 \mathrm{a}, \mathrm{c}$ ). It is distinct from the adjacent pretectum because of the gap of the posterior commissure and the absence of CBir cells and presence of highly packed CRir cells in the Co (fig. 2n, 3m, 8c, 9c). Caudal to the GT, the OT appeared narrow and poorly developed with restricted lamination, although it showed considerable rostrocaudal extension, as seen in saggital sections (fig. 8, 9). Rostrally it embraces the GT laterally, and caudally it extends far more than the mesencephalic tegmentum, covering the rostral rhombomeres (fig. $2 \mathrm{o}-\mathrm{v}, 3 \mathrm{~m}-\mathrm{s}$ ). The distinct CBir and CRir cells and fibers revealed some degree of lamination in the OT of Dermophis, but different layers were not completely segregated (fig. 5e, 6a, b). The distribution of the CBir-labeled structures extended all along the OT and formed a mixed population of weak and strong CBir cells (fig. 5e, 6a, d, 8a, b) which were more abundant and intense in the medial region of the OT. 

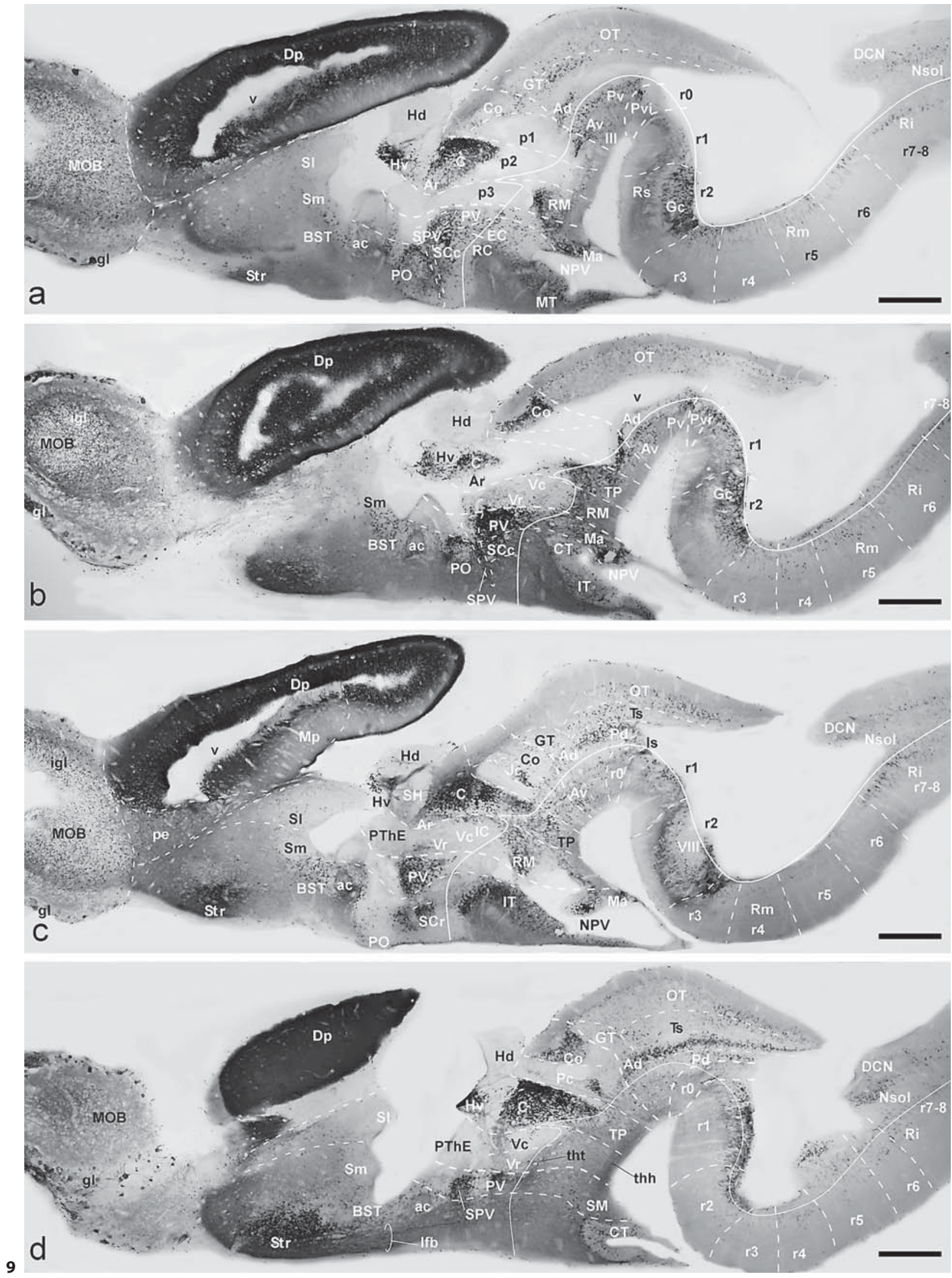
Also some CBir fibers were observed in an intermediate position within the thick fiber layer, leaving the outer and inner sublayers free of labeling (fig. 2q, arrowhead in 8a). Noticeably, CRir structures showed a more restricted distribution. Less numerous CRir tectal cells were distributed just beneath the thick fibrous layer (fig. 3o-r, 6b, 9ad) and were more densely grouped in the caudolateral portion of the tectum (fig. 6b). These cells were weakly CRir and were located in more lateral positions than the CBir cells (fig. 6a, b). Also some polygonal cells with large dendritic processes entering into the fiber layer were observed (fig. 6b). It is important to note that the retinal fibers that occupy the superficial part of the fiber zone [Himstedt and Manteuffel, 1985] were not labeled for CB or CR.

In gymnophionans there is not a clear distinction between the tectum proper and the torus semicircularis, and different toral nuclei are not distinguished [Roth et al., 1993]. As observed in sagittal sections, the rostrocaudal enlargement of the mesencephalic dorsal band also shaped the topologically caudal torus semicircularis, appearing as a thin structure lateroventral to the OT (fig. $2 p-u, 3 o-r, 8 b-d, 9 c, d$ ). This structure showed a characteristic differential distribution of $\mathrm{CB}$ and $\mathrm{CR}$ in a mostly complementary pattern, although some overlapping regions were also observed. CBir was more abundant in the caudal and lateral toral regions (fig. $2 \mathrm{p}-\mathrm{u}, 6 \mathrm{a}$, $\mathrm{d}, 8 \mathrm{c}$ ), whereas CRir structures occupied more rostral regions (fig. 3o, p, 9c, d).

The lateral band of the mesencephalon showed distinct CBir and CRir cell populations that delineated 2 clearly separated rostral and caudal divisions. Both proteins were abundant in cells of the anterodorsal nucleus (fig. 2o, 3n, 8, 9) and in the caudally located posterodorsal nucleus (fig. 2p, 3o, 5e, 8a, 9c), in which CRir was more abundant, particularly in the rostral half (fig. 9c). Additionally, a large laterocaudal group of small CBir neurons was observed in a migrated position in the lateral band, just rostral to the limit with the isthmus (fig. $2 \mathrm{q}-\mathrm{u}, 5 \mathrm{e}, 6 \mathrm{a}$, $\mathrm{d}, 8 \mathrm{~d})$. This nucleus has been named the laterocaudal mesencephalic nucleus by comparison with its counterpart similarly identified in reptiles [Díaz et al., 2000] and other amphibians [Morona and González, 2008].

Fig. 9. Parasagittal sections showing CRir cells and fibers in the brain of $D$. mexicanus, presented in lateromedial order (a-d). Dorsal is oriented upward and rostral to the left. The diencephalic prosomeres p1-p3, the isthmus and rhombomeres are delimited by dashed lines. The alar-basal boundary is indicated by a fine line. Scale bars $=1 \mathrm{~mm}$.

$\mathrm{CB}$ and $\mathrm{CR}$ in the Gymnophionan Brain
The basal band or tegmentum is much less developed than the previous alar bands because the accentuated mesencephalic flexure and the high rostrocaudal enlargement of the alar bands produce a wedge shape of the mesencephalon (fig. 1). In this division, numerous CBir and CRir cells were found in the anteroventral nucleus (fig. 2o, 5e, 8a, c, 9a-c). Noticeably, the CBir cells occupied more dorsal positions in this region and were less conspicuous than the CRir cells (fig. 8a-c, 9a-c). Numerous CBir and CRir cells were also found in the posteroventral tegmental nucleus. The CRir cells were widely distributed, whereas CBir cells were grouped slightly more dorsally and closer to the ventricle than the CRir cells, although many of them were intermingled (fig. 2q, 3o, 8a-c, 9a-c). Finally, in the medial band, some sparse CBir and more abundant CRir cells were observed in a ventral position that contains dopaminergic cells compared to the ventral tegmental area [González and Smeets, 1994] (fig. 2q, r, 3o, 10i).

\section{Isthmus}

The classically considered isthmus or isthmic region is here considered a single segment currently named rhombomere 0 (r0); in Dermophis it is curved because, besides the brain flexure, the isthmo-mesencephalic boundary is markedly oblique, as observed in sagittal sections (fig. 1, $8,9)$. Based on CB and CR immunohistochemistry it was possible to propose the most likely limits of this segment and distinguish some of its cell groups. In the alar region of $\mathrm{r} 0$, the isthmic nucleus is poorly developed in Dermophis [González et al., 2002a] and was distinct due to the lack of CBir and CRir elements (fig. 2s-v, 3p-r, 6a, c-e, $8 d, 9 d)$. Ventral to the isthmic nucleus, in the alar plate, there was a group that we named the posterodorsal isthmic nucleus (Pdi), following the nomenclature used in anurans and urodeles [Morona and González, 2009]. This nucleus contained a few CBir cells rostrally (fig. 6a) that were more numerous, packed, and intensely stained at caudal levels (fig. 6d). Within the basal plate, a distinct CBir group of periventricular cells was stained along $\mathrm{r} 0$, close to the alar-basal boundary (fig. 2s, 6a, d, 8a, d). This group was named the posteroventral isthmic nucleus (as in urodeles) and highlighted the isthmo-rhombencephalic boundary because these CBir cells continued caudally and laterally through a sharp transverse line (fig. 8c, d). CRir neurons were also found in the ventral portion of the posteroventral isthmic nucleus along $\mathrm{r} 0$ (fig. 3p, q, 6c). The caudal boundary of the isthmic segment was also evidenced by the intense CBir in the interpeduncular neuropil located in the $\mathrm{r} 1$ segment (fig. $8 \mathrm{c}, \mathrm{d}$ ).

Brain Behav Evol 2011;77:231-269 251 

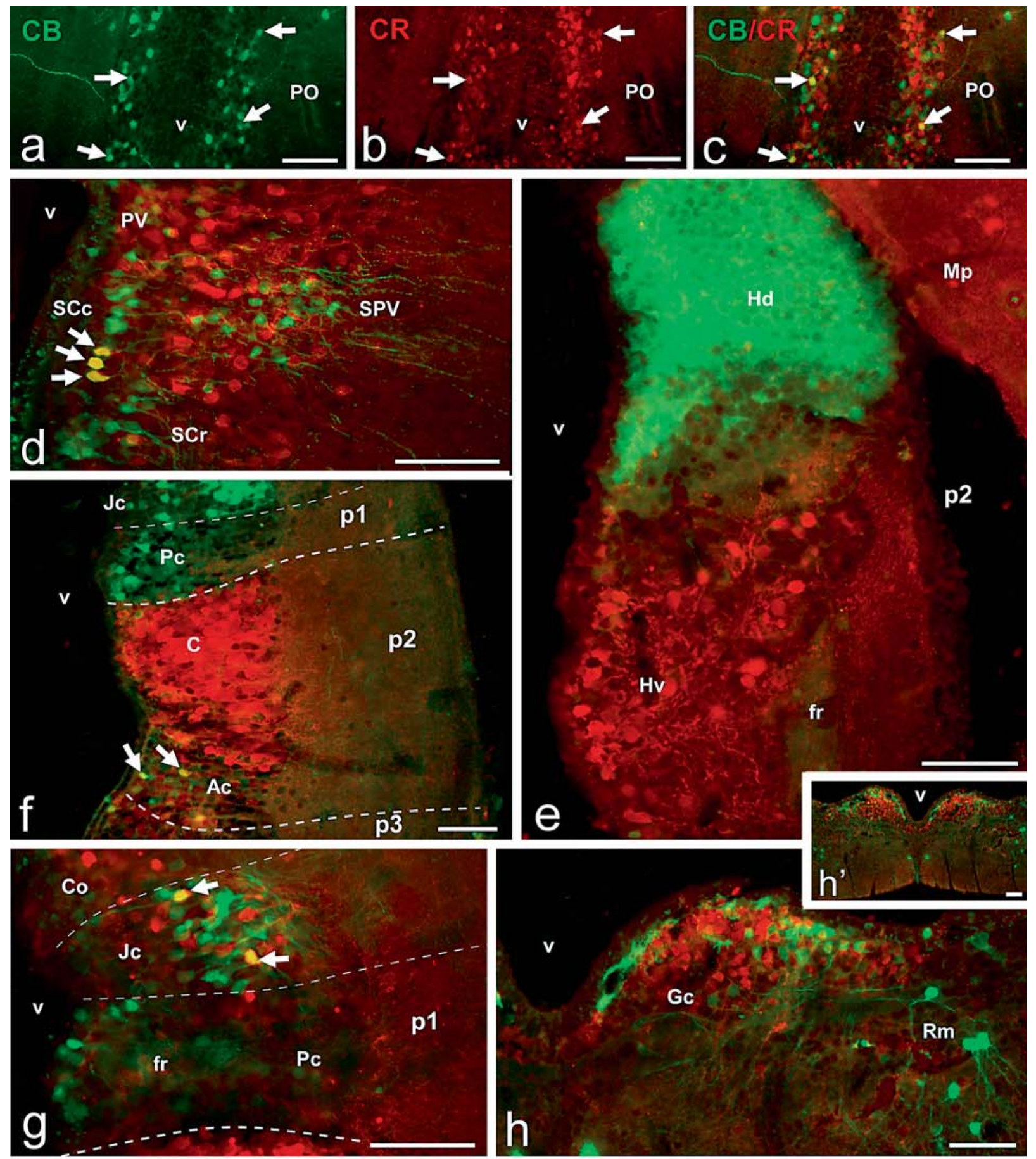

p1
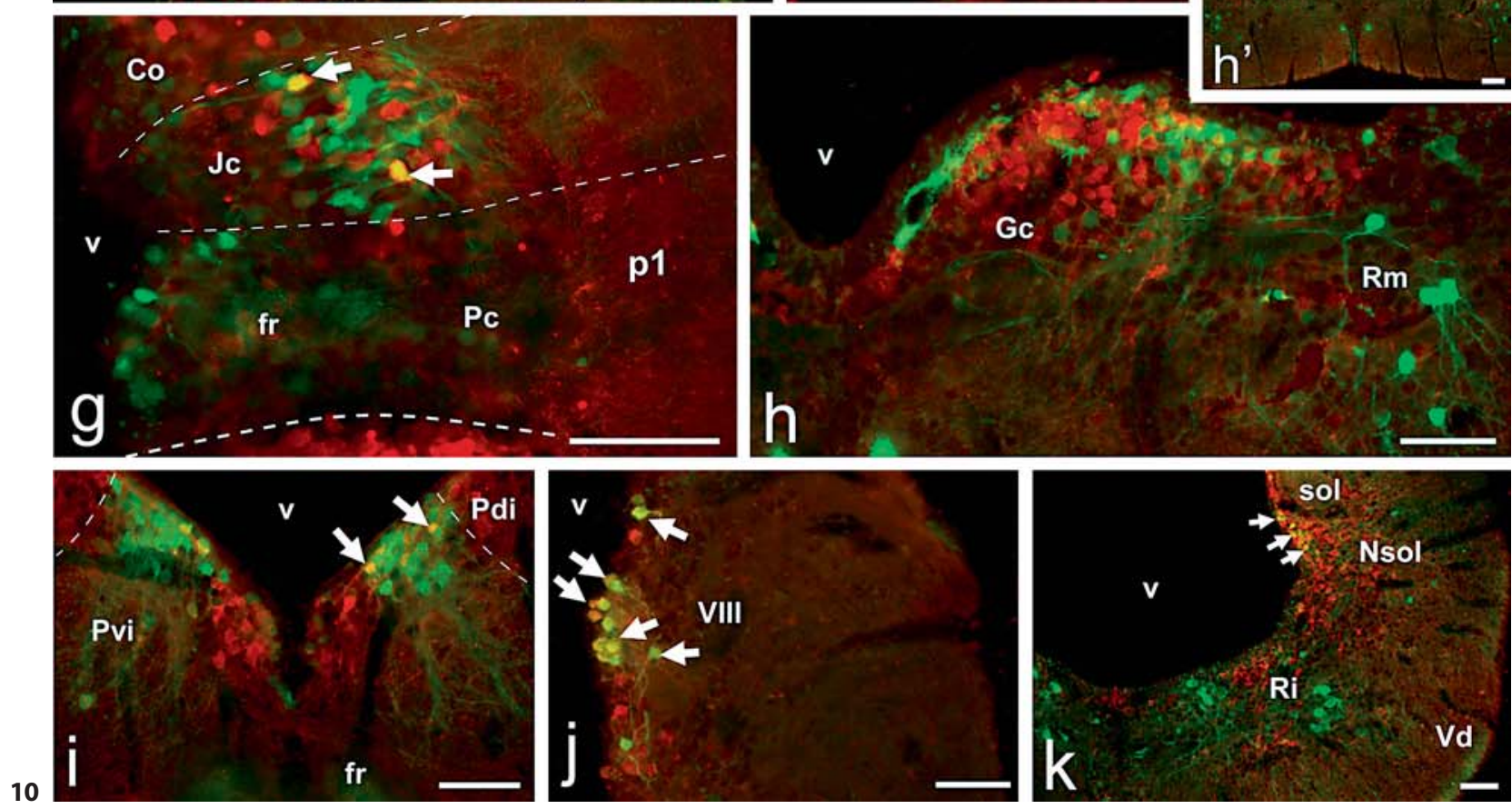


\section{Hindbrain}

This caudal part of the brainstem is formed by rhombomeres 1-7 (r1-r7) and a large r8, which is not clearly defined and probably represents more than one segment [Cambronero and Puelles, 2000]. We evaluated the spatial pattern of $\mathrm{CB}$ and $\mathrm{CR}$ immunoreactivity under this scheme, attending as well to the longitudinal organization within each segment; therefore, we will refer to alar and basal derivatives.

\section{Alar Derivatives}

The cerebellum originates in the rostral rhombic lip that develops bilaterally from the dorsolateral portions of the alar plates of $\mathrm{r} 1$ and $\mathrm{r} 2$ forming the cerebellar plate, and the subsequent growth causes the two rhombic lips to fuse in the midline to produce the lateral auriculae and the medial corpus cerebelli. In gymnophionans this structure has not been clearly identified cytoarchitectonically [Kühlenbeck, 1922, 1975, 1978] and only some laterally located cells in $\mathrm{rl}$ were proposed in Dermophis as a cerebellar nucleus because of their connections [SánchezCamacho et al., 2001]. In the other amphibian orders, it was corroborated that $\mathrm{CB}$ is constant in Purkinje cells in all species studied, particularly in the auricular lobes [Uray et al., 1998; Uray and Gona, 1999; Morona and González, 2009]. In Dermophis, clearly intense CBir cells appeared rostrally in the alar plate of rl. This region, located laterally in the dorsal and rostral edge, appeared as

Fig. 10. Photomicrographs of singly (a, b) and doubly (c-k) stained transverse sections through the brain of $D$. mexicanus that illustrates the degree of codistribution/colocalization of both proteins in different regions. a-c Preoptic CBir neurons immunolabeled in green (a) and CRir neurons immunostained in red (b) are widely intermingled, and only a few neurons were double labeled, as observed in yellow in the merged image (arrows in c). $\mathbf{d}$ Abundant codistribution of CBir and CRir cells in the hypothalamic areas and actual colocalization only in some cells of the caudal suprachiasmatic nucleus (arrows). e Complementary distribution of CBir and CRir cells and fibers in the habenula. $\mathbf{f}$ CB and CR localization in $\mathrm{p} 1$ and $\mathrm{p} 2$ shows only a restricted colocalization in the anterior nucleus of p2 (arrows). $\mathbf{g}$ Codistribution of CBir and CRir cells in the pretectum and actual colocalization only in some cells of the juxtacommissural nucleus. $\mathbf{h}, \mathbf{h}^{\prime}$ Codistribution of $\mathrm{CB}$ and $\mathrm{CR}$ at the Gc located in rhombomere $\mathrm{r} 2$, as observed in low $\left(\mathbf{h}^{\prime}\right)$ and high (h) magnifications. i Relative localization of CBir and CRir cells in the isthmic tegmentum and colocalization in Pvi (arrows). j Abundant CB/CR colocalization in cells of the octaval column in the rhombencephalic alar plate. $\mathbf{k}$ Simultaneous observation of the distribution of CBir and CRir cells and fibers in the caudal rhombencephalon (arrows point to doubly labeled cells in the nucleus of the solitary tract). Scale bars $=100 \mu \mathrm{m}$.

$\mathrm{CB}$ and $\mathrm{CR}$ in the Gymnophionan Brain the most intense labeled group for $\mathrm{CB}$ in $\mathrm{rl}$ and might represent a cerebellar primordium in the brain of Dermophis (Cb in fig. $2 \mathrm{v}, 7 \mathrm{a})$. The CB-labeled cells were arranged in a thin band that matched well with the gap left by the cholinergic and nitrergic cells of the laterodorsal tegmental nucleus (LDT) [González et al., 2002a, b] and the CRir cells of the parabrachial area $(\mathrm{Pb})$ (fig. $7 \mathrm{~b})$. Different cell types could not be distinguished in this reduced structure.

Within the alar region in $\mathrm{rl}$, CBir and CRir cells were found in the previously described LDT [González et al., $2002 \mathrm{a}, \mathrm{b}]$ and in close proximity to the locus coeruleus [González and Smeets, 1994] (fig. 2t, 3r, 6e, f). All through the length of the rhombencephalon, the alar plate contains the cell masses related to the octavolateral system in gymnophionans [Fritzsch, 1988; Fritzsch and Wake, 1988]. The organization of this area in adult Dermophis has not been studied but, by comparison with members of the same family, Caeciliidae (Boulengerula boulenger$u l i)$, in the continuous mass of undifferentiated periventricular cells the octaval projections would occupy the dorsalmost aspect of the alar plate because the lateral line system is not present [Fritzsch and Wake, 1988]. Only sparse CBir and CRir cells were detected along the alar plate of rhombomeres $\mathrm{r} 1$ and $\mathrm{r} 2$ and, in general, the rostral portion of the alar plate showed CRir neurons (fig. 3p-s, 6f) that were more numerous than the CBir cells (fig. $2 s-v$ ). Noticeable, intense CBir fibers were found in the alar $\mathrm{r} 1$ and extending into $\mathrm{r} 2$, probably next to the principal sensory trigeminal nucleus (fig. 8a). In the caudal rhombencephalon, labeled cells related to the octaval afferents were scarce and CBir fibers were labeled in the lateral aspect of the rhombencephalon that, along their course, were related to CBir cells located more medially and could be part of the descending trigeminal nucleus (fig. $2 \mathrm{u}-\mathrm{x}$ ). At caudal segments, a conspicuous cell population was labeled for CB and CR in the alar rhombencephalon that corresponded to the nucleus of the solitary tract (fig. $2 \mathrm{w}, \mathrm{x}, 3 \mathrm{u}, \mathrm{v}, 7 \mathrm{~h}-\mathrm{k}$ ). Also in the caudal alar region intense CBir cells were identified as the dorsal column nucleus by comparison with similarly located and stained cells in anurans and urodeles (fig. $2 \mathrm{y}, 7 \mathrm{i}, \mathrm{k}, 8$ ).

\section{Basal Derivatives}

In the basal rhombencephalon, distinct CBir and CRir populations were revealed. In the medial part of the rostral $\mathrm{rl}$, the interpeduncular nucleus contained CBir cells that were located above the CBir interpeduncular neuropil (fig. 2s, t, 6d, e, 8a, c). A distinct group of CBir cells occupied the medial dorsal portion in the griseum cen- 
trale (Gc), highlighting the rhombomeric boundaries, and were especially useful for identification of the rostral and caudal limits of $\mathrm{r} 2$ (fig. $2 \mathrm{u}, 6 \mathrm{a}, \mathrm{e}, 8 \mathrm{~b}$ ). These CBir small cells of the Gc were peripherally located with cell processes medially oriented to the central neuropil (fig. $2 \mathrm{u}$ ). Within the same medial position the disposition of the CRir cells in the Gc was similar, but actual colocalization was not demonstrated (fig. 3q, r, 9b). Migrated cells in the basal region in $\mathrm{r} 4$ and $\mathrm{r} 5$ were labeled for $\mathrm{CB}$ and, to a lesser extent, for CR (fig. 2v, 3s, 7e, f).

Along the rhombencephalic reticular formation, CBir and CRir cells were labeled. In general, CBir and CRir cells were found in several groups in the nucleus reticularis superior (fig. $2 \mathrm{u}, 3 \mathrm{r}, 6 \mathrm{e}, 7 \mathrm{c}$ ), in the nucleus reticularis medius (fig. $2 \mathrm{v}, \mathrm{w}, 3 \mathrm{~s}, \mathrm{t}, 7 \mathrm{c}-\mathrm{f}$ ), and in the nucleus reticularis inferior (fig. $2 \mathrm{x}, 3 \mathrm{u}, \mathrm{v}, 7 \mathrm{~g}, \mathrm{~h}$ ) that, as seen in sagittal sections, were arranged in regular clusters that respected rhombomeric boundaries (fig. 8c, d, 9a-d).

Low numbers of large cells were CBir and CRir within the basal plate that, compared with the distribution of ChAT immunoreactivity [González et al., 2002a], seemed to correspond to trigeminal and facial motor neurons (fig. $2 \mathrm{u}, \mathrm{w}, 3 \mathrm{r}, 7 \mathrm{~d}, \mathrm{e}$ ). This fact was supported by the observation of axons in the facial motor root (arrowhead in fig. 7e).

\section{Spinal Cord}

$\mathrm{CB}$ and CR labeled segregated populations in the rostral segments of the spinal cord that were analyzed. Both proteins labeled cell subpopulations of the dorsal and ventral gray horns (or fields since clear horns are not evident) and fibers in the different funiculi. CB was distributed in small rounded cells in the dorsal horn that possessed thin processes which were dorsally oriented (fig. 2z, 7l). The ventrally located CBir cells were evenly distributed. CRir spinal cells were located slightly laterally within the dorsal gray (fig. $3 \mathrm{w}$ ) and the population in the ventral gray consisted of some polygonal cells. CBir and CRir fibers were primarily labeled in the dorsolateral funiculus and, to a lesser extent, CBir fibers were also observed in the lateral funiculus (fig. $2 \mathrm{z}, 7 \mathrm{l}$ ).

\section{Double Immunohistochemistry}

The distribution of CBir and CRir cells in the brain of Dermophis suggested the possibility of colocalization in many regions, as observed in anurans and urodeles [Morona and González, 2008, 2009]. This prompted us to conduct double immunohistochemistry for the simultaneous detection of both proteins in the same sections (fig. 10). However, although CBir and CRir cells are inter- mingled in many regions, actual colocalization of both proteins in the same neurons could be demonstrated only in a few sets of neurons. Thus, double-labeled (CBir/CRir) neurons were detected in the preoptic area (fig. 10a-c) within the region that is close to the telencephalon and far from the alar-basal boundary. The caudal suprachiasmatic region also contained double-labeled cells close to the limit with the rostral subnucleus (fig. 10d).

The double immunofluorescence not only revealed double-labeled cells but also served to highlight the boundaries and subdivisions of some regions, i.e. specially outstanding within the diencephalic prosomeres. $\mathrm{CB}$ and CR showed a complementary pattern in the dorsal and ventral subdivisions of the habenula (fig. 10e) as well as in the thalamus (p2), where CB marked the rostral portion (Ar and Ac) that contained fewer CRir cells. Some of these neurons were double labeled just in the anterior caudal subdivision (fig. 10f).

$\mathrm{CB}$ also marked the juxtacommissural subdivision in the pretectum where some of the weak CRir cells were double labeled (fig. 10g). Although extensive overlapping was observed in some regions, as in the isthmic tegmentum and in the Gc (fig. 10h, h', i), most cells were single labeled (fig. 10h, h') and just a few cells contained both proteins in the posteroventral isthmic nucleus (fig. 10i). Other subpopulations of double-labeled cells in the rhombencephalon were more numerous. Rostrally, in the alar plate numerous rounded CBir/CRir cells were revealed in the octaval column (fig. 10j) and caudally in the region of the nucleus of the solitary tract (fig. 10k).

\section{Discussion}

In the present study we provide a detailed and comprehensive analysis of the distribution patterns of $\mathrm{CB}$ and CR in the central nervous system of the gymnophionan amphibian $D$. mexicanus. This work complements the previous studies performed in anurans and urodeles where a similar approach was used [Morona and González, 2008, 2009]. These patterns observed for representative species of the three amphibian orders share characteristic features with a notable order specificity but also show particularities in each species. Besides these differences, $\mathrm{CB}$ and $\mathrm{CR}$ immunoreactivities proved to be suitable markers for delimiting particular brain areas from their neighboring territories, which are otherwise indistinguishable, and allowed the identification of labeled cell groups within certain regions that support distinct subdivisions. 
For understanding the distribution patterns for $\mathrm{CB}$ and CR in Dermophis, we used the previous studies of Milán and Puelles [2000] and Morona and González $[2008,2009]$ as a guide for the interpretation of the novel information in this most neglected amphibian order.

In the following sections, the general organization and variations of the CBir and CRir structures in amphibians are discussed, primarily pointing out the distinct features found in Dermophis. We specifically attend to the current ideas for the regionalization of the forebrain and brainstem. Although it is not the aim of the present study to deal extensively with the detailed distribution of these proteins in other vertebrates, some comments will be made when needed to assess common versus specific features of amphibians and, in particular, of Dermophis.

\section{Olfactory Bulbs}

A feature shared by the three orders of amphibians is the abundant CR immunoreactivity found in primary olfactory and vomeronasal fibers and in many cells and fibers distributed equally in the MOB and $\mathrm{AOB}$, with an abundance of labeled neurons in the internal granular cell layer [Marín et al., 1998; Necchi et al., 1999; Brox et al., 2003, Mühlenbrock-Lenter et al., 2005; Morona and González, 2008]. However, a difference with anurans and urodeles was noted in Dermophis where periglomerular and mitral cells were not stained for CB or CR [Morona and González, 2008].

The presence of $\mathrm{CR}$ in the olfactory receptors, olfactory nerve fibers, and bulbar glomeruli seems to be a characteristic shared by anamniotes [Kerschbaum and Hermann, 1992; Díaz-Regueira and Anadón, 2000; Pombal et al., 2002; Castro et al., 2003, 2006; Huesa et al., 2006; present results]. As in amphibians, diversity exists with regard to the presence of CR in bulbar cells of fish because both interneurons and mitral cells contain CR in lampreys [Pombal et al., 2002] and some teleosts [Porteros et al., 1997; Díaz-Regueira and Anadón, 2000], whereas only scarce CRir interneurons were demonstrated in a chondostrean fish [Huesa et al., 2006] and no CRir cells were detected in the zebrafish and catfish olfactory bulbs [Castro et al., 2006; Jadhao and Malz, 2007]. The numerous studies conducted in different mammalian species also show enormous diversity in the content of $\mathrm{CB}$ and CR in bulbar cell populations [Alonso et al., 1993, 1995; Malz et al., 2000; Jia and Halpern, 2004; Parrish-Aungst et al., 2007]. However, it is a shared feature that the periglomerular cells are always rich in CB and CR [Briñón et al., 1992; Alonso et al., 1993; Toida et al., 1998; Kakuta et al., 2001; Jia and Halpern, 2004; Kosaka and Kosaka,
2007], whereas species differences exist regarding the localization of these proteins in granule cells [Kakuta et al., 2001; Jia and Halpern, 2004].

\section{Pallium}

In concordance with the observation in anurans and urodeles, the pallium of Dermophis possesses low numbers of CBir cells and, in contrast to the members of the other two orders, almost completely lacks CBir in the large medial pallium [Morona and González, 2008]. In turn, the population of CRir cells located in the dorsal and lateral pallial areas of Dermophis largely resembles the situation found in the two urodele species studied, highlighting the closer resemblance between the pallial regions of urodeles and gymnophionans, as previously proposed [Northcutt and Kicliter, 1980]. Moreover, the pattern of fiber labeling in the pallium is also similar in urodeles and Dermophis, in which a long fiber bundle and terminal field intensely stained for CR occupies the superficial zone of the medial, dorsal, and, to a lesser extent, lateral pallial regions [Morona and González, 2008]. It is noteworthy that the pattern of distribution of CR in Dermophis helped to highlight the boundary between the medial and dorsal pallia, which was controversial in classical studies [Kühlenbeck, 1922; Welsch and Tan, 1979; Northcutt and Kicliter, 1980].

Cortical subpopulations of neurons in amniotes are distinctly labeled for $\mathrm{CB}$ and $\mathrm{CR}$, making the study of the distribution of these CBPs of special significance for establishing cell types and cortical subdivisions [Dávila et al., 1997, 1999; DeFelipe, 1997; Chiry et al., 2003; Krutzfeldt and Wild, 2004; Suárez et al., 2006]. In general, different types of nonpiramidal neurons are stained for each protein and display different neurochemical characteristics [Martínez-Guijarro and Freund, 1992; DeFelipe, 1997; Guirado and Dávila, 1999; Wild et al., 2005; Suárez et al., 2006; Rahman and Baizer, 2007]. Strikingly different to amniotes are the results described for nonamphibian anamniotes in which CBP-containing cells are absent or very scarce in pallial regions [Díaz-Regueira and Anadón, 2000]. However, as we have observed in Dermophis, CR is significatively present in pallial subdivisions of the zebrafish, and the localization of CRir has shown that cytoarchitectonic subdivisions of the dorsal telencephalon can be differentiated by their content in CRir structures [Castro et al., 2006].

With regard to the innervation of the pallium by CRir fibers in the three amphibian orders, it should be mentioned that it largely resembles the innervation of cortical regions of reptiles [Dávila et al., 1997, 1999]. However, in 
reptiles the CRir fibers and terminals that formed the characteristic cortical band were suggested to have originated in the cholinergic basal telencephalic cell population because terminals containing acetylcholine distribute in the reptilian cortex forming a band similar to that observed for CR (and CB) [Dávila et al., 1997]. In Dermophis, as in other amphibians, although a basal forebrain cholinergic cell group has been demonstrated, the pattern of innervation of the pallium does not resemble that observed for CR or CB [Marín et al., 1997; González and López, 2002; González et al., 2002a; Sánchez-Camacho et al., 2006]. According to our results in Dermophis, this pallial innervation most likely arises in intrapallial neurons or in the abundant CRir thalamic cells, as also proposed for anurans and urodeles [Morona and González, 2008].

\section{Septum}

The large septal region in Dermophis formed, together with the medial pallium, a bulge into the lateral ventricle that was virtually devoid of CR- and CB-containing cells and fibers. Only the rostralmost part of the septum contains a distinct CBir cell population that by its position and in comparison with results in anurans [Morona and González, 2008] may represent the counterpart of the anuran postolfactory eminence, as proposed earlier [Northcutt and Kicliter, 1980]. The actual boundary between the medial pallium and the septal region located just below is hard to distinguish and becomes evident only when immunohistochemistry for the detection of several peptides is used [González et al., 2002b; López et al., 2006, 2007]. The largest septal region of gymnophionans was considered homologous to the lateral septal nucleus of anurans on the basis of its abundant catecholaminergic innervation and lack of cholinergic and $\mathrm{GnRH}$ immunoreactive cells [González and Smeets, 1994; Pinelli et al., 1997; Rastogi et al., 1998; Ebersole and Boyd, 2000; González et al., 2002a]. This region almost totally lacks CBir or CRir cells or fibers, as was also observed in the lateral septal region of urodeles [Morona and González, 2008]. Differently, abundant septal CRir and CBir cell populations in anurans distribute differently within distinct nuclei [Sánchez-Camacho et al., 2003, 2006; Endepols et al., 2006]. Interestingly, the caudally located and shrunken septal region of Dermophis would correspond with the medial septal nucleus which contains, in addition to the CRir cell population demonstrated in the present study, GnRH immunoreactive cells and cholinergic and nitrergic neurons, as in anurans and urodeles [Marín et al., 1997; Rastogi et al., 1998; González et al., 2002a, b]. It should be kept in mind that in urodeles, while Pleurodeles is virtually devoid of labeled cells in the septum, Ambystoma possesses both CRir and CBir cells restricted to the medial septal region [Morona and González, 2008]. Therefore, as in all other brain regions, the situation found in Dermophis should not be generalized for all other gymnophionan species. Major differences are noted in the lateral septal area in terms of $\mathrm{CB}$ and $\mathrm{CR}$ immunoreactivity between amniotes and amphibians [Riedel et al., 2002], whereas the presence of CRir cells in the medial septum is a shared feature of tetrapods [Kiss et al., 1997; Borhegyi and Freund, 1998]. Moreover, considering the scarce data available for other anamniotes, the CRir cells localized in the ventrolateral telencephalic region of the trout, together with other neurochemical data, support that this nucleus of teleosts is a homolog of some medial septal neuronal populations in tetrapods [Castro et al., 2003].

\section{Basal Ganglia}

In the basal ganglia of gymnophionans only the striatum proper could be distinguished in studies based on classical methods [Kühlenbeck, 1922; Northcutt and Kicliter, 1980]. By means of immunohistochemistry to unravel the distribution of catecholamines, acetylcholine, and several peptides, a nucleus accumbens was proposed rostrally in the hemispheres, just medial to the ventral tip of the lateral ventricles [González and Smeets, 1994; González et al., 1994; González et al., 2002a, b; López et al., 2006, 2007]. However, tract-tracing studies and specific stainings to unravel possible pallidal zones in the basal telencephalon have not been conducted in gymnophionans. Our study has corroborated that the striatum of Dermophis is a large structure in the ventrolateral hemisphere that contains moderate numbers of CBir and CRir cells and is conspicuously innervated by terminals labeled mainly for CR. This distribution basically coincides with those observed in anurans and urodeles [Marín et al., 1998; Brox et al., 2003; Morona and González, 2008]. However, the amount and intensity of CR staining in the striatal neuropil is less conspicuous in Dermophis, suggesting that the thalamostriatal CR-containing projection is not as abundant as in the other amphibians. The distribution of CBir and CRir cells in the striatum and in the region identified as possible nucleus accumbens supports the idea of an especially well-developed striatal region in gymnophionans, as previously evidenced by the distribution, for example, of catecholaminergic and nitrergic structures [González and Smeets, 1994; González et al., 1994; 2002a]. 
As previously noted, information about the localization of pallidal structures in the gymnophionan basal ganglia is lacking. In contrast, on the basis of the localization of the transcription factor $\mathrm{Nkx} 2.1$ in anurans and urodeles, the position of the pallidal region has been identified [González et al., 2002c, d; Moreno and González, 2007a] as in amniotes [Price, 1993; Sussel et al., 1999; Puelles et al., 2000]. By comparison, the putative pallidal region of Dermophis would be situated in the caudal hemisphere, close to the amygdaloid territories, and would derive from the ventromedial ventricular zone. It is noteworthy that the recently identified pallidal region of urodeles contains a particular CBir cell population [Moreno and González, 2007a; Morona and González, 2008] and similarly labeled cells are located in comparable regions of Dermophis, although their pallidal nature awaits neurochemical and hodological confirmation.

In amniotes, the distribution of the large populations of CB- and CR-containing cells has served to evaluate distinct chemoarchitectonic and functional domains within the complex organization of the basal ganglia [Holt et al., 1997; Hontanilla et al., 1998; Morel et al., 2002]. It was generally corroborated that most CRir cells in the striatum are interneurons [Bennett and Bolam, 1993; Figueredo-Cardenas et al., 1996; Cicchetti et al., 1998, 2000], whereas subpopulations of CBir-projecting cells were reported in primates [Parent et al., 1996; Cicchetti et al., 2000; Cooper and Stanford, 2002]. The characterization of the CBir and CRir striatal cells as interneurons or projecting neurons has not been investigated in any group of amphibians. Information about CBP distribution in other groups of anamniotes is very scarce, but the presence of CR has served to clarify the putative localization of the striatum in the ventral telencephalon of the trout [Castro et al., 2003]. Moreover, in a recent study of the telencephalon of lungfish, a small CBir cell population was found in the striatum that contrasted with the abundance of CRir fibers and terminals located in the striatal neuropil, thus resembling the situation found in the three amphibian orders [González and Northcutt, 2009; unpubl. results].

\section{Amygdaloid Complex}

In the present study we have tentatively differentiated 3 (lateral, central, and medial) amygdaloid regions within the caudal telencephalon in a position that almost totally corresponds with the previously named 'pars lateralis of the amygdala' [Northcutt and Kicliter, 1980]. This subdivision was prompted by the distinct distribution of diverse markers in the telencephalon of gymnophionans
[González and Smeets, 1994; González et al., 2002a, b; López et al., 2006, 2007] and by comparison with anurans and urodeles [Moreno and González, 2006, 2007a]. The lateral amygdala was defined as a multimodal area in the ventral pallium [Moreno and González, 2004] and the actual ventral pallial origin of this region was confirmed by the expression of territorial genetic markers [SmithFernandez et al., 1998; Brox et al., 2004; Moreno et al., 2004]. The distinct pattern of CB and CR distribution in combination with the detection of nitrergic structures has served to identify the lateral amygdala from its neighboring pallial and subpallial regions in anuran and urodele amphibians [Moreno and González, 2004, 2007a; Morona and González, 2008]. In Dermophis, a distinct region between the lateral pallium and the striatum contains densely labeled cells and fibers for nitric oxide synthase immunohistochemistry that would correspond to the ventropallial region containing the lateral amygdala [González et al., 2002b]. In our present study, both CBir and CRir cells were clearly observed in this region, between the lateral pallium and the striatum, supporting the comparison with other amphibians. The presence of CBir and CRir cells in this region is shared by the three amphibian orders, but the pattern observed in Dermophis is more similar to that in urodeles, where the CRir cells also extended more caudally accompanied by the nitrergic neuropil, whereas CBir cells occupied only the rostral part. This situation could suggest a subdivision within this area.

The central amygdala of anuran and urodele amphibians is currently interpreted, like in amniotes, as the striatal component of the amygdaloid complex [Moreno and González, 2005, 2006] and the presence of CBir and CRir cells in this region follows the pattern observed in the striatum [Morona and González, 2008]. In Dermophis, the proposed central amygdala would represent the caudal part of the large striatal region described on the basis of cytoarchitectonics [Northcutt and Kicliter, 1980] and contains CBir and CRir cells distributed as a caudal continuation of the striatal cells. Although the connectivity of this region has not been investigated in gymnophionans, in the other amphibians is particularly connected with brainstem centers [Moreno and González, 2005]. The caudal 'striatal' cells that were revealed to posses long descending projections in gymnophionans likely correspond to actual central amygdaloid cells [Wicht and Himstedt, 1988; Sánchez-Camacho et al., 2001].

The medial amygdala has been redefined in amphibians as the main vomeronasal center receiving secondary information from the $\mathrm{AOB}$ and comprises a large part of 
the early named pars lateralis of the amygdala in all amphibians [Northcutt and Kicliter, 1980; ten Donkelaar, 1998a, b; Moreno and González, 2003, 2006]. The pattern of CBir and CRir cells observed in Dermophis in a similar location suggests that the medial amygdala is a large structure that extends caudally in the hemisphere. The possible enlargement of this vomeronasal amygdaloid territory is not surprising considering the large $\mathrm{AOB}$ of gymnophionans that have been related to the presence of a specific tentacle associated with the vomeronasal organ and the vomeronasal chemoreception [Badenhorst, 1978; Billo and Wake, 1987]. This unique organ appears to be very important in the ecology of the gymnophionans, and thus primary and secondary centers of the sensory vomeronasal information are consequently well developed.

Finally, most of the previously described 'pars medialis of the amygdala' in the caudal telencephalon of gymnophionans has been considered here as a putative BST by comparison with the similarly located nucleus in anurans identified by its connections and neurochemistry, including the distribution of CB and CR [Marín et al., 1998; Moreno et al., 2011], which concurs with the observations made in the present study in Dermophis.

The distinct distribution of CBPs in the amygdaloid complex of diverse amniotes has served as an anatomical marker to define subterritories [Sorvari et al., 1996a, b; Kemppainen and Pitkanen, 2000; Ashwell et al., 2005; Legaz et al., 2005]. However, many species differences were described that made impossible the use of CBPs to propose homologies, although their distribution constitutes a good anatomical tool. Among anamniotes, the 3 amygdaloid regions described for amphibians have been recently proposed in lungfish and the coelacanth Latimeria columnae [Northcutt, 2008; González and Northcutt, 2009; Northcutt and González, 2011] and the distribution of $\mathrm{CB}$ and $\mathrm{CR}$, at least in lungfish, supports their distinction. In contrast, the telencephalon in actinopterygian fish undergoes an eversion process instead of the evagination that occurs in other vertebrates; thus, the teleostean mediodorsal pallium would correspond, as a whole, to the lateroventral pallium of 'evaginated brains'. In different works, homologies for the teleostean pallium have been postulated and recently reviewed by Northcutt [2008]. However, in amphibians and teleosts, the distribution of CBPs in the telencephalon is strikingly different and it is not possible to establish regional comparisons on the basis of distinct locations for $\mathrm{CB}$ and $\mathrm{CR}$.

\section{Nontelencephalic Secondary Prosencephalon and Hypothalamus}

Most studies in gymnophionans have highlighted the great expansion of the hypothalamus, including the suprachiasmatic and preoptic regions, that in some cases was observed to be more distinctly organized into segregated cell groups than in urodeles [González and Smeets, 1997; Pinelli et al., 1997; Hilscher-Conklin et al., 1998; Ebersole and Boyd, 2000; Ebersole et al., 2001; Muñoz et al., 2001; Rastogi et al., 2001; López et al., 2006]. The present study has revealed that the distribution of $\mathrm{CB}$ and $\mathrm{CR}$ within this set of regions allows the distinction of most of the cell groups identified in anurans and urodeles [Milán and Puelles, 2000; Morona and González, 2008]. Thus, in the preoptic area, the basically segregated distribution of CBir and CRir cells suggests further subdivisions of this large region, as previously proposed in anurans and in concordance with results in amniotes [Celio, 1990; Fortin and Parent, 1997; Cheng et al., 2003; Huesa et al., 2006; Morona and González, 2008; Real et al., 2008]. Moreover, the subdivision of the preoptic area in Dermophis is suggested by the distinct distribution of other neurochemicals, such as tyrosine hydroxylase and nitric oxide synthase, that specifically label regions within the preoptic area distinct from those labeled for the CBPs [González and Smeets, 1994; González et al., 2002b].

Particularly abundant are the CBir and CRir cells located in the suprachiasmatic region. As already noted, the identification of a clear optic chiasm in Dermophis is arduous because the reduced number of fibers that constitute the optic nerves and only a small ridge, at best, can be localized in sagittal sections. However, the distribution of many neuropeptides and other chemical markers allows recognition of a similar suprachiasmatic 'nucleus' in gymnophionans that topologically corresponds to its counterparts in other vertebrates. The content of CBPs, particularly $\mathrm{CB}$, in the suprachiasmatic nucleus has been related to the control of circadian rhythms [LeSauter et al., 1999; Arvanitogiannis et al., 2000; Bryant et al., 2000; LeSauter et al., 2009; Stadler et al., 2010]. This nucleus is the primary circadian pacemaker that reinforces their oscillations and synchronizes its components in response to light input [Welsh et al., 2010]. In spite of their fossorial life, light detection may still play an important role in the lives of these 'blind' animals for circadian entrainment or setting seasonal rhythms. Results obtained in some studies in other fossorial vertebrates support this hypothesis [Cooper et al., 1993; Herbin et al., 1994; Crish et al., 2006].

The distribution of CB and CR led us to consider the recently coined term supraoptoparaventricular region as 
a band between the preoptic area and the suprachiasmatic region that contains the magnocellular neurosecretory nucleus and stains distinctly for other markers [González et al., 1994; González and Smeets, 1997; Hilscher-Conklin et al., 1998; Muñoz et al., 2001; López et al., 2007]. This band is histogenetically distinctly specified during development in a manner that has been shown to be constant at least for tetrapods [Bardet et al., 2008].

The large basal hypothalamus of Dermophis shares with that of anurans and, to a lesser extent, with that of urodeles the presence of abundant CBir and CRir cells distributed in the median, intermediate, and caudal tuberal nuclei [Morona and González, 2008]. In addition, the CBir cell population located in the caudal basal hypothalamus in the lateral and mammillary region is outstanding in Dermophis, and fibers from this labeled cell group seem to originate projections to the thalamus and the medial telencephalic wall.

Comparatively, in the same manner as that described for mammals [Puelles and Rubenstein, 2003], the pattern of bands distinguished in the alar part of the hypothalamus by means of $\mathrm{CB}$ and $\mathrm{CR}$ immunohistochemistry would correspond to actual longitudinal bands because of the distinct brain flexures. Similar analysis in other groups of vertebrates would serve to highlight the constancy of these regions.

Particularly abundant CBir and CRir cells have been localized in the infundibular nuclei of mammalian and nonmammalian species [Celio, 1990; Résibois and Rogers, 1992; Rogers and Résibois, 1992; Fortin and Parent, 1997; Castro et al., 2006], which is in concordance with the results in amphibians. It is noteworthy that the mammillary projection to the anterior thalamic region in mammals is essential for spatial memory [Vann and Aggleton, 2003] and learning [Méndez-López et al., 2009]. The observed CBir fibers connecting the mammillary region with the thalamus in Dermophis might also play a role in spatial memory functions. Interestingly, some parts of the lateral mammillary nucleus has also been involved in the regulation of neurons in the respiratory center of rats' medulla during hypoxia, and CB-containing cells could be implicated in this function [Arutiunian et al., 2009]. One of the adaptations to fossorial life is a very extended cutaneus respiration due to the extreme hypoxia and hypercapnia in some subterranean environments.

\section{Diencephalon}

In anurans and urodeles, diencephalic regions have been analyzed in relation to their content of CB and CR, and a similar regionalization was proposed in both orders [Milán and Puelles, 2000; Morona and González, 2008]. Thus the CB and CR patterns helped to define subregions in the relatively simple diencephalon of urodeles in spite of the limited neuronal migration that makes it difficult to demarcate separate nuclei. In the diencephalon of gymnophionans, the neuronal arrangement is similar to that in urodeles; thus, its study presents analogous difficulties [Schmidt and Wake, 1991; Roth et al., 1993]. Our material clearly delineates previously unidentified nuclei by the distinct distribution of $\mathrm{CB}$ and $\mathrm{CR}$ compared with previously reported immunohistochemical maps [Clairambault et al., 1994; González et al., 1994; González et al., 2002b]; however, the patterns of CB and CR distribution often vary with respect to those found in other amphibians.

Most neuroanatomical studies of the brain of gymnophionans used a classical nomenclature, indirectly assuming a straight rostrocaudal axis and 4 basic longitudinal zones: the epithalamus, the dorsal thalamus, the ventral thalamus, and the hypothalamus [Clairambault et al., 1994; Ebersole, et al., 2001; López et al., 2006, 2007]. On the other hand, the segmental interpretation was used to frame the results of very few works [González et al., 2002a, b]. However, the most recent studies of the brain of amphibians take great advantage of the use of the prosomeric model [Puelles and Rubenstein, 2003] that facilitates the interpretation of the diencephalic cell groups [Puelles et al., 1996; Milán and Puelles, 2000; Brox et al., 2004; Moreno et al., 2004; Morona and González, 2008, 2009]. Therefore, in our analysis of the distribution of CB and $\mathrm{CR}$ we tested the capacity of the prosomeric model to interpret the organization of the diencephalon of Dermophis. The new interpretation of the diencephalic cell groups and their localization within particular prosomeres is proposed mainly on the basis of the data about the distribution of $\mathrm{CB}$ and $\mathrm{CR}$ and their comparison with similar data in anurans and urodeles [Morona and González, 2008].

In the interpretation of the diencephalic subdivisions, the prethalamic eminence and the BSM represent the dorsal portion of the prosomere p3. The BSM of Dermophis is specifically identified by the CB immunohistochemistry, in line with the situation found in anurans and urodeles. Also shared by the three amphibian orders is the relatively scarce distribution of CBir and CRir elements in the alar part of $\mathrm{p} 3$ (former ventral thalamus). A striking pattern of $\mathrm{CB}$ and $\mathrm{CR}$ distribution is present in the p2 of Dermphis. CBir cells and fibers are restricted to the dorsal habenula, whereas CRir elements are located 
in the ventral habenula, and no asymmetry exists between right and left habenulae. Comparatively, this pattern is almost similar to that found in urodeles, although clear asymmetry was noted in the two species studied [Morona and González, 2008]. Differently, in anurans the dorsal habenula does not posses CBir elements and no asymmetry was noted [Milán and Puelles, 2000; Morona and González, 2008]. However, the three amphibian orders share the intense CR immunoreactivity present in the alar p2 (thalamus) and the codistribution with $\mathrm{CB}$ delineates similar subdivisions. Also in the large alar p1 (pretectum), the distinct distribution of $\mathrm{CB}$ and $\mathrm{CR}$ in Dermophis can be framed within the newly described tripartite subdivision established for anurans [Morona et al., 2011].

The labeling obtained in the diencephalon of Dermophis has served to assess a rather conservative pattern among amphibians. Comparisons with previous data in anamniote and amniote representatives highlight, again, species variations regarding the specific distribution for each CBP. However the different immunostaining allows (in most cases) clear distinction between prethalamus (p3), thalamus (p2), and pretectum (p1), as well as subdivisions within them, that respect and are well explained by the prosomeric model [Pombal and Puelles, 1999; Dávila et al., 2000; Milán and Puelles, 2000; González et al., 2002; Castro et al., 2006; Morona and González, 2008]. A main trait of the distribution of these proteins in the diencephalon is the abundant presence of CR in thalamic neurons in anamniotes [present results; Pombal and Puelles, 1999; Díaz-Regueira and Anadón, 2000; Milán and Puelles, 2000; Castro et al., 2006], whereas in amniotes CB prevails in the thalamus [Braun, 1990; Pritz and Stritzel, 1991; Pritz and Siadati, 1999; Dávila et al., 2000; Münkle et al., 2000; González et al., 2002]. Within the alar part of $\mathrm{pl}$, the distribution of CB and CR in Dermophis seemed to match well with the 3 molecularly distinct anteroposterior domains already recognized in several vertebrate groups [Pombal and Puelles, 1999; Dávila et al., 2000; Milán and Puelles, 2000; Ferrán et al., 2007; Morona et al., 2011]. The large size and distinct organization of the pretectal region of Dermophis was particularly striking because this region was associated with optokinetic reflexes in amphibians [Cochran et al., 1984; Manteuffel et al., 1986; Sperl and Manteuffel, 1987; Jardon and Bonaventure, 1992, 1997] that in Dermophis are supposed to be reduced due to the minimized visual system [Himstedt and Manteuffel, 1985; Milner, 2001]. However, the pretectum is also related to orientation in prey-catching behavior [Grobstein and Comer, 1983;
Ewert, 2001], which can be of special significance in Dermophis.

\section{Mesencephalon}

The identification of the rostral and caudal boundaries of the mesencephalon in Dermophis allowed us to correctly interpret different subdivisions. The diencephalomesencephalic boundary was highlighted by the $\mathrm{CB}$ immunoreactivity in the mesencephalic nuclei limiting with the diencephalon. This boundary is bent rostrally in the roof plate and protrudes in the basal plate of $\mathrm{p} 1$ at the level of the basal band.

The GT is distinct due to the particular localization of CBir and CRir cells. This region can thus be recognized in Dermophis like in other vertebrates [Puelles et al., 1996; Díaz et al., 2000; Díaz-Regueira and Anadón, 2000; Milán and Puelles, 2000; García-Calero et al., 2002]. In the OT, CBir cells were more abundant than CRir cells in all amphibians studied. In Dermophis, the CBir and CRir cells are segregated within the apparently undifferentiated periventricular cell layer. Studies on the mesencephalic tectum of gymnophionans [Schmidt and Wake, 1991] suggested that the tectum of these animals possesses an 'intermediate' degree of morphological complexity between anurans and urodeles, and the distribution of the studied CBPs support this idea because practically no segregation was found in urodeles and a complex distribution of CBir and CRir cells was observed in anurans [Morona and González, 2009]. If the situation in Dermophis is similar to that in Ichthyophis [Himstedt and Manteuffel, 1985] the retinal axons in the tectum are restricted to the medial and superficial zone and, therefore, they are not labeled for $\mathrm{CB}$ and $\mathrm{CR}$. This is in striking contrast with the strong CR labeling in the retinorecipient tectal layer in anurans and urodeles [Necchi et al., 1999; Morona and González, 2009]. Moreover, the CR content of retinofugal fibers seems to be a common characteristic in other vertebrates [Rogers and Résibois, 1992; Leuba and Saini, 1997; De Castro et al., 1998; Díaz-Regueira and Anadón, 2000; Soares et al., 2001; Kang et al., 2002; García-Crespo and Vecino, 2004; Puelles et al., 2004; Castro et al., 2006; Lee et al., 2006; Jadaho and Malz, 2007; Morona and González, 2009]. The CRir fibers in the tectal retinorecipient layer have been correlated with the presence of abundant CRir ganglion cells in the retina [Gábriel et al., 1998; Morona et al., 2007b], but the lack (or presence) of CRir ganglion cells in Dermophis has not been investigated. Finally, in the OT of Dermophis trigeminal mesencephalic cells were not labeled for CB or $\mathrm{CR}$ as in urodeles and some anurans; actually, only in 
Xenopus is a subpopulation of trigeminal mesencephalic cells CBir, and most of these neurons project to the spinal cord [Morona et al., 2006a].

In gymnophionans the torus semicircularis is not conspicuous and its distinction from the OT is not clearly marked cytoarchitectonically [Roth et al., 1993]. However, the analysis that we have conducted based on the longitudinal organization of the mesencephalon that is better interpreted in sagittal sections has allowed its distinction in Dermophis, mainly due to the pattern of CB and $\mathrm{CR}$ distribution. Thus, in the topologically located dorsal band, the torus semicircularis possesses distinct CRir cells rostrally and CBir cells caudally and this segregated pattern largely resembles that observed in anurans where the torus is highly developed [Morona and González, 2009]. In anurans, the sensory significance of the nuclei that comprise the torus semicircularis is known and the distribution of these proteins in toral nuclei could be related to the processing of acoustic or lateral line information. However, adult Dermophis have most likely completely lost the lateral line system [Fritzsch, 1988] and, therefore, the torus semicircularis would be a main octaval sencondary center but acoustic and vestibular regions have not been determined. At this point we can assume toral parcelation as observed for $\mathrm{CB}$ and $\mathrm{CR}$ distribution, but the implication of each subzone in a specific type of sensory information has to be investigated. Comparatively, the distinct distribution of $\mathrm{CB}$ and CR has been useful for analysis of particular cell groups in the torus not only in amphibians but also in the chick [Puelles et al., 1994].

Due to the cephalic flexure, the tegmental bands of gymnophionans are reduced and show a much shorter rostrocaudal extent than the dorsal bands. Distinct CBir and CRir cell populations show that the tegmentum can be easily subdivided into anterior and posterior nuclei, in line with the organization found in anurans and urodeles [Morona and González, 2009]. Also abundant tegmental cell populations containing $\mathrm{CB}$ and $\mathrm{CR}$ have been described in different vertebrates [García-Segura et al., 1984; Celio, 1990; Résibois and Rogers, 1992; DíazRegueira and Anadón, 2000; Castro et al., 2006]. In particular, 3 main tegmental groups have been especially addressed in several studies: the $\mathrm{RN}$, the oculomotor nucleus, and the catecholaminergic A9-A10 group (substantia nigra and ventral tegmental area) [Brauth et al., 1988; Celio, 1990; McRitchie et al., 1996; Wang et al., 1996; De la Cruz et al., 1998; Verney et al., 2001]. The RN is a major component of the rostral portion of the basal mesencephalic band [Díaz et al., 2000] and it was tenta- tively identified in Dermophis by its contralateral projection to the spinal cord [Sánchez-Camacho et al., 2001], but these cells were clearly migrated from the ventricle into a position devoid of CBir and CRir cells [present results]. The oculomotor nucleus of Dermophis is formed by a low number of motoneurons arranged close to the ventricle in the basal band [González et al., 2002a] and, according to the present results, only partial colocalization with the CRir cells (the most ventrally located in the ventral band) could exist, although corroboration is needed by double-labeling techniques. In other amphibians variability has been found because CB is present in some oculomotor cells of anurans, whereas CR and $\mathrm{CB}$ are located in subpopulations of oculomotor neurons in urodeles [Morona and González, 2009]. Taking into consideration that double labeling was not performed in other studies, some oculomotor neurons in mammals were described to contain CB in rats [Celio, 1990] and cats [De la Cruz et al., 1998], and no CRir oculomotor cells were found [Arai et al., 1991]. In contrast, CB is absent in oculomotor cells in birds [Fujii and Lucaj, 1993], and CR is present in this nucleus in teleosts [Díaz-Regueira and Anadón, 2000; Castro et al., 2006]. Therefore, the variability shown for amphibians is also common among other vertebrates.

Finally, in the mesencephalon of gymnophionans, a strikingly large group of catecholaminergic cells (putative dopaminergic) was described in the medial band [González and Smeets, 1994] and it was correlated with the intense innervation of the striatum [Wicht and Himstedt, 1988; González et al., 1994]. Since double labeling for the simultaneous detection of catecholaminergic markers and CB and CR has not been conducted in Dermophis, we can not rule out colocalization in some of the ventromedially located cells. Again, without double-labeling techniques, the dopaminergic mesencephalic cell groups of mammals were reported to contain numerous CRir [Résibois and Rogers, 1992] and CBir cells [Celio, 1990; McRitchie et al., 1996; Verney et al., 2001].

\section{Isthmus}

The isthmus, as considered here ( $\mathrm{r} 0)$, is a thin and oblique segment in other amphibians, but in gymnophionans the curvature is more accentuated. The sharp curve of the rostrocaudal axis and the large development of the dorsal mesencephalon cause an irregular obliquity of this boundary, and actual isthmic nuclei were classically included in the mesencephalic or in the rhombencephalic tegmentum. In the alar part of the isthmus, the isthmic nucleus as identified by its cholinergic cells 
[González et al., 2002a] is very reduced, like most visual centers in gymnophionans [Himstedt and Manteuffel, 1985; Roth et al., 1993], and no CBir or CRir cells are located in a similar position. This observation is in agreement with the lack of $\mathrm{CB}$ and $\mathrm{CR}$ in the homologous nucleus of other amphibians and other vertebrate groups [Celio, 1990; Díaz-Regueira and Anadón, 2000; Castro et al., 2006; Morona and González, 2009]. Like in anurans and urodeles, the isthmic tegmentum of Dermophis shows CBir and CRir cells as caudal continuations of the mesencephalic groups (Pdi and Pvi). In turn, the trochlear nucleus, characteristic of the basal tegmentum [González et al., 2002a], seems to be devoid of CB and CR. It is important to note that only $1 \%$ of the trochlear motoneurons in the cat contain CB [De la Cruz et al., 1998] and no data are available in other vertebrates.

\section{Hindbrain}

In accordance with previous studies in amphibians [Marín et al., 1997; Straka et al., 2006; Morona and González, 2009] we consider the isthmo-rhombencephalic boundary as described above and the rhombencephalon starting rostrally in the large segment rl. Many derivatives have been described in $\mathrm{rl}$ that are distinct enough to have received an anatomical name. This is especially observed in those derivatives of the alar plate that include cholinergic cell groups, the locus coeruleus, the parabrachial complex, the main sensory trigeminal nucleus, part of the rostral octaval column, and lateral parts of the corpus cerebelli and the auriculae [Aroca and $\mathrm{Pu}$ elles, 2005]. Moreover, the tegmentum is characterized by the absence of motoneurons and the presence of the interpeduncular nucleus. By means of CB and CR immunohistochemistry, we could distinguish some of those components in the $\mathrm{rl}$ of Dermophis and analyze their correct topological localization.

In the alar part of $\mathrm{rl}$, a cholinergic and nitrergic cell group was described previously in the 'isthmic' region misplacing the boundaries [González et al., 2002a, b]. Comparing the distribution of the cholinergic and nitrergic cells with the CBir and CRir cell populations [own observations], most of the cholinergic cells actually belong to rl, and they most likely correspond to the LDT, as defined in other vertebrates [Aroca and Puelles, 2005]. Among the cells of this nucleus, a minor subpopulation most likely colocalizes CB or CR, as found in other amphibians [Morona and González, 2009] and mammals [Nemcová et al., 1997; Fortin and Parent, 1999].

Another $\mathrm{rl}$ derivative is the locus coeruleus. This noradrenergic group was described next to the LDT in the 'isthmic' region [González and Smeets, 1994]. CB and CR cells are located in a similar position in Dermophis; however, no double labeling was performed to corroborate the colocalization. In other amphibians, double-labeling experiments for CB and CR with tyrosine hydroxylase corroborated that the locus coeruleus neurons do not possess CB or CR [Morona and González, 2009]. CBir and CRir cells are also present along the alar plate of $\mathrm{rl}$ in Dermophis in topological positions similar to where the octavolateral nuclei, the parabrachial nucleus (area), and the main sensory trigeminal nucleus were described in anurans and urodeles [Morona and González, 2009].

Many studies in amphibians and other vertebrates corroborated the presence of CB and CR in different cerebellar cell types. Specifically, CB is a good marker of Purkinje cells [Fortin et al., 1998; Schmidt et al., 2005, 2007], whereas CR is found mainly in other cell types as granular [Gall et al., 2003], unipolar, brush, and Lugaro cells [Résibois and Rogers, 1992; Schiffmann et al., 1999], except in primates where some subpopulations of Purkinje cells are CRir [Fortin et al., 1998]. In all species of amphibians studied so far CB is present in Purkinje cells and some granule cells [Uray et al., 1998; Uray and Gona, 1999; Morona and González, 2009] and particularly in Rana but not in Xenopus laevis, and urodeles Purkinje cells contain CR [Necchi et al., 1999; Uray and Gona, 1999; Morona and González, 2009]. However, the cerebellum of gymnophionans is so poorly developed that several studies have suggested that it might be absent altogether [Fritzsch and Sontag, 1987; Roth et al., 1993]. In Dermophis we observed a small population of CBir cells with long processes that because of its position might be regarded as a plausible candidate for a minimal cerebellum in these animals.

In the basal region of $\mathrm{rl}$, the interpeduncular nucleus and neuropil of Dermophis contain noticeable CBir fibers originated in the dorsal habenula and coursing in the fasciculus retroflexus, like in urodeles [Morona and González, 2008, 2009]. The particularly intense staining for $\mathrm{CB}$ and $\mathrm{CR}$ in segregated populations of the central gray cells is a shared feature observed in the $\mathrm{rl}$ of other amphibians and teleosts [Díaz-Regueira and Anadón, 2000; Castro et al., 2006; Morona and González, 2009].

Along the basal part of the rhombencephalon, a column of CBir and CRir cells is present in Dermophis, as in other vertebrates. Its extent across rhombomeres can be assessed by localization of the motor nuclei and nerve roots [González et al., 2002a]. Most likely, many of these cells correspond to reticulospinal cells [Sánchez-Cama- 
cho et al., 2001], as demonstrated in other vertebrates [Goodchild et al., 2000; Morona et al., 2006b, 2007a]. Also in the basal part of the rhombencephalon, comparison of the distribution of CBir and CRir cells with the location and size of the motoneurons in the trigeminal and facial nuclei strongly support colocalization, although it was not corroborated by double-labeling experiments. In addition, as proposed for the other orders of amphibians, the efferent cells of the octaval nerve could also be CBir or CRir in Dermophis according to their position [Fritzsch and Crapon de Caprona, 1984].

Throughout the rhombencephalon, in the dorsal part of the alar plate, mixed populations of CBir and CRir are present in the undifferentiated octaval column of Dermophis [Fritzsch, 1988]. This situation contrasts with that observed in anurans and urodeles because, in those species that retain the lateral line system in the adult, CR is particularly related to the mechanoreceptive lateral line cells and primary fibers, whereas CB is mainly present in octaval cells and fibers. In addition, the anurans that have lost the lateral line system through metamorphosis show CR immunoreactivity mainly in acoustic fibers and nuclei, whereas $\mathrm{CB}$ is mainly present in vestibular fibers and nuclei [Morona and González, 2009]. As previously noted, adult Dermophis most likely do not posses a lateral line system and the present results suggest that the vestibular and acoustic information are not well segregated in the rhombencephalic alar plate.

Caudally in the alar plate of Dermophis, distinct labeling for $\mathrm{CB}$ and $\mathrm{CR}$ was found in the nucleus of the solitary tract and the dorsal column nucleus, as defined by their content in cholinergic, catecholaminergic, and nitrergic cells [González and Smeets, 1994; González et al., 2002a, b]. This feature seems to be shared by all amphibians and concurs with data reported in mammals [Crockett et al., 1996; Magnusson et al., 1996; Kawai and Semba, 1999; Morona and González, 2009].

\section{Spinal Cord}

The abundant CBir and CRir spinal cells revealed in Dermophis are distinctly distributed in the dorsal and ventral gray fields largely resembling the situation found in urodeles and lungfish [Morona and González, 2009; Morona et al., 2010]. Significantly, in anurans the distribution of $\mathrm{CB}$ and $\mathrm{CR}$ in the spinal cord includes a variety of cells with different localizations and morphologies in close resemblance with the distributions reported in amniotes [Morona and González, 2006a].

\section{Concluding Remarks}

The present study has corroborated that the distribution of CB and CR observed in D. mexicanus conforms to the overall amphibian pattern, but it has also demonstrated that within the class Amphibia remarkable differences exist. It should also be noted that, as was observed for anurans and urodeles, we can not characterize gymnophionans based on work on a single species because important species differences may exist in the distribution of these CBPs. It also becomes clear that before referring to specific 'amphibian' patterns of brain organization one should include data from the much neglected group of amphibians, the gymnophionans.

The immunohistochemical technique for detection of $\mathrm{CB}$ and $\mathrm{CR}$ used in our study was confirmed as a powerful tool in the identification of cell groups and brain structures that are otherwise indistinct in the brain of Dermophis. In addition, the consistent paradigm considered for comparing brain regions has served to clarify, in many cases, the principal criterion for the determination of homology, i.e. similarity in position [Nieuwenhuys, 1998]. However, particularly in gymnophionans, the identification of many neuronal condensations or nuclei cannot be made cytoarchitectonically due to restricted cell segregation from the periventricular region [Roth et al., 1993]. Therefore, immunocytochemically identified neuron populations compared across species represent a useful auxiliary tool that gives important clues in relation to the homology of brain nuclei [Nieuwenhuys, 1998]. However, it should be pointed out that straightforward comparisons based only on the presence of CBPs should not be made, due to the great variability observed in wellestablished homologous regions in the brain of different vertebrates (see above). Nevertheless, in cases of unclear topological relations, this immunohistochemical approach has been valuable to confirm homology [Dávila et al., 2000; Milán and Puelles, 2000; Puelles and Rubenstein, 2003; Morona and González, 2008, 2009].

\section{Acknowledgements}

We are grateful to Prof. R.G. Northcutt (Scripps Institution of Oceanography, UCSD) for his help in obtaining some specimens of $D$. mexicanus. This research was supported by the Spanish Ministry of Science and Technology (grant No. BFU2009-1231/ BFI). 


\section{References}

-Adams JC (1981): Heavy metal intensification of DAB-based HRP reaction product. J Histochem Cytochem 29:775.

-Alonso JR, Arévalo R, García-Ojeda E, Porteros A, Briñón JG, Aijón J (1995): NADPH-diaphorase active and calbindin D-28k-immunoreactive neurons and fibers in the olfactory bulb of the hedgehog (Erinaceus europaeus). J Comp Neurol 351:307-327.

-Alonso JR, Arévalo R, Porteros A, Briñón JG, Lara J, Aijón J (1993): Calbindin D-28K and NADPH-diaphorase activity are localized in different populations of periglomerular cells in the rat olfactory bulb. J Chem Neuroanat $6: 1-6$.

Andressen C, Blumcke I, Celio MR (1993): Calcium-binding proteins: selective markers of nerve cells. Cell Tissue Res 271:181-208.

-Arai R, Jacobowitz DM, Deura S (1994): Distribution of calretinin, calbindin-D28k, and parvalbumin in the rat thalamus. Brain Res Bull 33:595-614.

-Arai R, Winsky L, Arai M, Jacobowitz DM (1991): Immunohistochemical localization of calretinin in the rat hindbrain. J Comp Neurol 310:21-44.

Aroca P, Puelles L (2005): Postulated boundaries and differential fate in the developing rostral hindbrain. Brain Res Brain Res Rev 49:179_ 190.

-Arutiunian RS, Akopian NS, Adamian N, Karapetian MA (2009): Determination of the role of the hypothalamic lateral mammilar nucleus in regulation of neurons in the respiratory center of rat's medulla during hypoxia. Aviakosm Ekolog Med 43:50-55.

-Arvanitogiannis A, Robinson B, Beaule C, Amir S (2000): Calbindin-D28k immunoreactivity in the suprachiasmatic nucleus and the circadian response to constant light in the rat. Neuroscience 99:397-401.

-Ashwell KW, Hardman CD, Paxinos G (2005): Cyto- and chemoarchitecture of the amygdala of a monotreme, Tachyglossus aculeatus (the short-beaked echidna). J Chem Neuroanat 30:82-104.

Badenhorst A (1978): The development and the phylogeny of the organ of Jacobson and the tentacular apparatue of Zchthyophis glutinosus (Linne). Ann Univ Stellenbosch Ser A2 (Soologie) 1:1-26.

- Baimbridge KG, Celio MR, Rogers JH (1992): Calcium-binding proteins in the nervous system. Trends Neurosci 15:303-308.

-Bardet SM, Martínez-de-la-Torre M, Northcutt RG, Rubenstein JL, Puelles L (2008): Conserved pattern of OTP-positive cells in the paraventricular nucleus and other hypothalamic sites of tetrapods. Brain Res Bull 75: 231-235.

Bennett BD, Bolam JP (1993): Characterization of calretinin-immunoreactive structures in the striatum of the rat. Brain Res 609:137148 .
Billo R, Wake MH (1987): Tentacle development in Dermophis mexicanus (Amphibia: Gymnophiona: Caecililidae). J Morphol 192:101111.

Bolt JR (1991): Lissamphibian origins; in Schultze HP, Trueb L (eds): Origins of the Major Groups of Tetrapods: Controversies and Consensus. Ithaca, Cornell University Press, pp 194-222.

Borhegyi Z, Freund TF (1998): Dual projection from the medial septum to the supramammillary nucleus in the rat. Brain Res Bull 46: 453-459.

Braun K (1990): Calcium-binding proteins in avian and mammalian central nervous system: localization, development and possible functions. Prog Histochem Cytochem 21:164.

Brauth SE, Kitt CA, Gerfen CR (1988): Calcium binding protein in the basal ganglia system of a non-mammalian vertebrate: an immunohistochemical study in the reptile Caiman crocodilus. Brain Res 452:367-372.

Briñón JG, Alonso JR, Arévalo R, García-Ojeda E, Lara J, Aijón J (1992): Calbindin D-28kpositive neurons in the rat olfactory bulb: an immunohistochemical study. Cell Tissue Res 269:289-297.

Brox A, Puelles L, Ferreiro B, Medina L (2003): Expression of the genes GAD67 and Distalless- 4 in the forebrain of Xenopus laevis confirms a common pattern in tetrapods. J Comp Neurol 461:370-393.

Brox A, Puelles L, Ferreiro B, Medina L (2004). Expression of the genes Emx1, Tbrl, and Eomes (Tbr2) in the telencephalon of Xenopus laevis confirms the existence of a ventral pallial division in all tetrapods. J Comp Neurol 474:562-577.

Bryant DN, LeSauter J, Silver R, Romero MT (2000): Retinal innervation of calbindinD28K cells in the hamster suprachiasmatic nucleus: ultrastructural characterization. J Biol Rhythms 15:103-111.

Cambronero F, Puelles L (2000): Rostrocaudal nuclear relationships in the avian medulla oblongata: a fate map with quail chick chimeras. J Comp Neurol 427:522-545.

Castro A, Becerra M, Manso MJ, Anadón R (2003): Distribution and development of calretinin-like immunoreactivity in the telencephalon of the brown trout, Salmo trutta fario. J Comp Neurol 467:254-269.

Castro A, Becerra M, Manso MJ, Anadón R (2006): Calretinin immunoreactivity in the brain of the zebrafish, Danio rerio: distribution and comparison with some neuropeptides and neurotransmitter-synthesizing enzymes. 1. Olfactory organ and forebrain. J Comp Neurol 494:435-459.

Celio MR (1990): Calbindin D-28k and parvalbumin in the rat nervous system. Neuroscience 35:375-475.
Cheng G, Marotte LR, Ashwell KW (2003): Cyto- and chemoarchitecture of the hypothalamus of a wallaby (Macropus eugenii) with special emphasis on oxytocin and vasopressinergic neurons. Anat Embryol (Berl) 207:233-253.

Chiry O, Tardif E, Magistretti PJ, Clarke S (2003): Patterns of calcium-binding proteins support parallel and hierarchical organization of human auditory areas. Eur J Neurosci 17:397-410.

Cicchetti F, Beach TG, Parent A (1998): Chemical phenotype of calretinin interneurons in the human striatum. Synapse 30:284-297.

Cicchetti F, Prensa L, Wu Y, Parent A (2000): Chemical anatomy of striatal interneurons in normal individuals and in patients with Huntington's disease. Brain Res Rev 34:80-101.

-Clairambault P, Christophe N, Pairault C, Herbin M, Ward R, Reperant J (1994): Organization of the serotoninergic system in the brain of two amphibian species, Ambystoma mexicanum (Urodela) and Typhlonectes compressicauda (Gymnophiona). Anat Embryol (Berl) 190:87-99.

Cochran SL, Dieringer N, Precht W (1984): Basic optokinetic-ocular reflex pathways in the frog. J Neurosci 4:43-57.

Cooper AJ, Stanford IM (2002): Calbindin D-28k positive projection neurones and calretinin positive interneurones of the rat globus pallidus. Brain Res 929:243-251.

Cooper HM, Herbin M, Nevo E (1993): Ocular regression conceals adaptive progression of the visual system in a blind subterranean mammal. Nature 361:156-159.

Crish SD, Dengler-Crish CM, Comer CM (2006): Population coding strategies and involvement of the superior colliculus in the tactile orienting behavior of naked mole-rats. Neuroscience 139:1461-1466.

Crockett DP, Maslany S, Egger MD (1996): Synaptophysin immunoreactivity and distributions of calcium-binding proteins highlight the functional organization of the rat's dorsal column nuclei. Brain Res 707:31-46.

Dávila JC, Guirado S, Puelles L (2000): Expression of calcium-binding proteins in the diencephalon of the lizard Psammodromus algirus. J Comp Neurol 427:67-92.

Dávila JC, Padial J, Andreu MJ, Guirado S (1999): Calbindin-D28k in cortical regions of the lizard Psammodromus algirus. J Comp Neurol 405:61-74.

Dávila JC, Padial J, Andreu MJ, Real MA, Guirado S (1997): Calretinin immunoreactivity in the cerebral cortex of the lizard Psammodromus algirus: a light and electron microscopic study. J Comp Neurol 382:382-393.

De Biasi S, Arcelli P, Spreafico R (1994): Parvalbumin immunoreactivity in the thalamus of guinea pig: light and electron microscopic correlation with gamma-aminobutyric acid immunoreactivity. J Comp Neurol 348:556569. 
-De Castro F, Cobos I, Puelles L, Martínez S (1998): Calretinin in pretecto- and olivocerebellar projections in the chick: immunohistochemical and experimental study. J Comp Neurol 397:149-162.

DeFelipe J (1997): Types of neurons, synaptic connections and chemical characteristics of cells immunoreactive for calbindin-D28K, parvalbumin and calretinin in the neocortex. J Chem Neuroanat 14:1-19.

-De la Cruz RR, Pastor AM, Martínez-Guijarro FJ, López-García C, Delgado-García JM (1998): Localization of parvalbumin, calretinin, and calbindin $\mathrm{D}-28 \mathrm{k}$ in identified extraocular motoneurons and internuclear neurons of the cat. J Comp Neurol 390:377391.

DDíaz C, Yanes C, Trujillo CM, Puelles L (2000): Cytoarchitectonic subdivisions in the subtectal midbrain of the lizard Gallotia galloti. J Neurocytol 29:569-593.

Díaz-Regueira S, Anadón R (2000): Calretinin expression in specific neuronal systems in the brain of an advanced teleost, the grey mullet (Chelon labrosus). J Comp Neurol 426:81-105.

Duellman WE, Trueb L (1994): Biology of Amphibians. Baltimore, Johns Hopkins University Press.

-Ebersole TJ, Boyd SK (2000): Immunocytochemical localization of gonadotropin-releasing hormones in the brain of a viviparous caecilian amphibian, Typhonectes natans (Amphibia: Gymnophiona). Brain Behav Evol 55:14-25.

-Ebersole TJ, Conlon JM, Goetz FW, Boyd SK (2001): Characterization and distribution of neuropeptide $\mathrm{Y}$ in the brain of a caecilian amphibian. Peptides 22:325-334.

-Edmonds B, Reyes R, Schwaller B, Roberts WM (2000): Calretinin modifies presynaptic calcium signaling in frog saccular hair cells. Nat Neurosci 3:786-790.

-Endepols H, Muhlenbrock-Lenter S, Roth G, Walkowiak W (2006): The septal complex of the fire-bellied toad Bombina orientalis: chemoarchitecture. J Chem Neuroanat 31:5976.

Engelhardt F (1924): Tentakelapparat und Auge von Ichthyophis. Jena Z Naturwiss 60:241305.

- Ewert JP, Buxbaum-Conradi H, Dreisvogt F, Glagow M, Merkel-Harff C, Röttgen A, Schürg-Pfeiffer E, Schwippert WW (2001): Neural modulation of visuomotor funcions underlying prey-catching behaviour in anurans: perception, attention, motor performance, learning. Comp Biochem Physiol A Mol Integr Physiol 128:417-461.

Feller AE, Hedges SB (1998): Molecular evidence for the early history of living amphibians. Mol Phylogenet Evol 9:509-516.

-Ferran JL, Sánchez-Arrones L, Sandoval JE, Puelles L (2007): A model of early molecular regionalization in the chicken embryonic pretectum. J Comp Neurol 505:379-403.
Figueredo-Cardenas G, Medina L, Reiner A (1996): Calretinin is largely localized to a unique population of striatal interneurons in rats. Brain Res 709:145-150.

Fortin M, Marchand R, Parent A (1998): Calcium-binding proteins in primate cerebellum. Neurosci Res 30:155-168.

Fortin M, Parent A (1997): Distribution of calretinin, calbindin-D28k and parvalbumin in the hypothalamus of the squirrel monkey. J Chem Neuroanat 14:51-61.

Fortin M, Parent A (1999): Calretinin-immunoreactive neurons in primate pedunculopontine and laterodorsal tegmental nuclei. Neuroscience 88:535-547.

-Fournet N, García-Segura LM, Norman AW, Orci L (1986): Selective localization of calcium-binding protein in human brainstem, cerebellum and spinal cord. Brain Res 399: 310-316.

Fritzsch B (1988): The amphibian octavo-lateralis system and its regressive and progressive evolution. Acta Biol Hung 39:305-322.

Fritzsch B (1998): Of mice and genes: evolution of vertebrate brain development. Brain Behav Evol 52:207-217.

Fritzsch B, Crapon de Caprona D (1984): The origin of centrifugal inner ear fibers of Gymnophions (Amphibia): a horseradish peroxidase study. Neurosci Lett 46:131-136.

Fritzsch B, Sonntag R (1987): The trochlear nerve of amphibians and its relation to proprioceptive fibers: a qualitative and quantitative HRP study. Anat Embryol (Berl) 177: 105-114.

Fritzsch B, Wake MH (1988): The inner ear of gymnophione amphibians and its nerve supply: a comparative study of regressive events in a complex sensory system (Amphibia, Gymnophiona). Zoomorphology 108:201217.

Frost DR (2007): Amphibian species of the world: an online reference, version 5.1. New York, American Museum of Natural History. http://research.amnh.org/herpetology/amphibia/index.php.

Fujii JT, Lucaj Z (1993): Calcium-binding proteins in the chick Edinger Westphal nucleus. Brain Res 605:200-206.

Gábriel R, Volgyi B, Pollak E (1998): Calretininimmunoreactive elements in the retina and optic tectum of the frog, Rana esculenta. Brain Res 782:53-62.

Gall D, Roussel C, Susa I, D’Angelo E, Rossi P, Bearzatto B, Galas MC, Blum D, Schurmans S, Schiffmann SN (2003): Altered neuronal excitability in cerebellar granule cells of mice lacking calretinin. J Neurosci 23:93209327.

García-Calero E, Martínez-de-la-Torre M, Puelles L (2002): The avian griseum tectale: cytoarchitecture, NOS expression and neurogenesis. Brain Res Bull 57:353-357.

García-Crespo D, Vecino E (2004): Differential expression of calretinin in the developing and regenerating zebrafish visual system. Histol Histopathol 19:1193-1199.
García-Segura LM, Baetens D, Roth J, Norman AW, Orci L (1984): Immunohistochemical mapping of calcium-binding protein immunoreactivity in the rat central nervous system. Brain Res 296:75-86.

Gilland E, Baker R (1993): Conservation of neuroepithelial and mesodermal segments in the embryonic vertebrate head. Acta Anat (Basel) 148:110-123.

González A, López JM (2002): A forerunner of septohippocampal cholinergic system is present in amphibians. Neurosci Lett 327: 111-114.

-González A, López JM, Marín O (2002d): Expression pattern of homeobox gene Nkx-2.1 in the forebrain of Xenopus laevis during development. Brain Res Gene Expr Patterns 1: 181-185.

González A, López JM, Sánchez-Camacho C Marín O (2002a): Localization of choline acetyltransferase (ChAT) immunoreactivity in the brain of a caecilian amphibian, Dermophis mexicanus (Amphibia: Gymnophiona). J Comp Neurol 448:249-267.

-González A, López JM, Sánchez-Camacho C, Marín O (2002c): Regional expression of the homeobox gene NKX2-1 defines pallidal and interneuronal populations in the basal ganglia of amphibians. Neuroscience 114: 567-575.

González A, Moreno N, López JM (2002b): Distribution of NADPH-diaphorase/nitric oxide synthase in the brain of the caecilian Dermophis mexicanus (Amphibia: Gymnophiona): comparative aspects in amphibians. Brain Behav Evol 60:80-100.

-González A, Muñoz M, Muñoz A, Marín O, Smeets WJ (1994): On the basal ganglia of amphibians: dopaminergic mesostriatal projections. Eur J Morphol 32:271-274.

González A, Northcutt RG (2009): An immunohistochemical approach to lungfish telencephalic organization. Brain Behav Evol 74: 43-55.

González A, Smeets WJ (1994): Distribution of tyrosine hydroxylase immunoreactivity in the brain of Typhlonectes compressicauda (Amphibia, Gymnophiona): further assessment of primitive and derived traits of amphibian catecholamine systems. J Chem Neuroanat 8:19-32.

-González A, Smeets WJ (1997): Distribution of vasotocin- and mesotocin-like immunoreactivities in the brain of Typhlonectes compressicauda (Amphibia, Gymnophiona): further assessment of primitive and derived traits of amphibian neuropeptidergic systems. Cell Tissue Res 287:305-314

-González G, Puelles L, Medina L (2002): Organization of the mouse dorsal thalamus based on topology, calretinin immunostaining, and gene expression. Brain Res Bull 57:439442. 
-Goodchild AK, Llewellyn-Smith IJ, Sun QJ, Chalmers J, Cunningham AM, Pilowsky PM (2000): Calbindin-immunoreactive neurons in the reticular formation of the rat brainstem: catecholamine content and spinal projections. J Comp Neurol 424:547-562.

-Guirado S, Dávila JC (1999): GABAergic cell types in the lizard hippocampus. Eur J Morphol 37:89-94.

-Grobstein P, Comer C (1983): The nucleus isthmi as an intertectal relay for the ipsilateral oculotectal projection in the frog, Rana pipiens. J Comp Neurol 217:54-74.

- Gutiérrez C, Yaun A, Cusick CG (1995): Neurochemical subdivisions of the inferior pulvinar in macaque monkeys. J Comp Neurol 363:545-562.

-Hay JM, Ruvinsky I, Hedges SB, Maxson LR (1995): Phylogenetic relationships of amphibian families inferred from DNA sequences of mitochondrial $12 \mathrm{~S}$ and $16 \mathrm{~S}$ ribosomal RNA genes. Mol Biol Evol 12:928-937.

Hedges SB, Moberg KD, Maxson LR (1990): Tetrapod phylogeny inferred from $18 \mathrm{~S}$ and $28 \mathrm{~S}$ ribosomal RNA sequences and a review of the evidence for amniote relationships. Mol Biol Evol 7:607-633.

-Hedges SB, Nussbaum RA, Maxson LR (1993): Caecilian phylogeny and biogeography inferred from mitochondrial DNA sequences of the 12S rRNA and 16S rRNA genes (Amphibia: Gymnophiona). Herpetol Monogr 7: 64-76.

-Heizmann CW, Braun K (1992): Changes in $\mathrm{Ca}(2+)$-binding proteins in human neurodegenerative disorders. Trends Neurosci 15: 259-264.

-Herbin M, Reperant J, Cooper HM (1994): Visual system of the fossorial mole-lemmings, Ellobius talpinus and Ellobius lutescens. J Comp Neurol 346:253-275.

-Hilscher-Conklin C, Conlon JM, Boyd SK (1998): Identification and localization of neurohypophysial peptides in the brain of a caecilian amphibian Typhlonectes natans (Amphibian: Gymnophiona). J Comp Neurol 394:139-151.

Himstedt W (1996): Die Blindwühlen. Magdeburg, Westarp.

-Himstedt W, Manteuffel G (1985): Retinal projections in the caecilian Ichthyophis kohtaoensis (Amphibia, Gymnophiona). Cell Tissue Res 239:689-692.

Holt DJ, Graybiel AM, Saper CB (1997): Neurochemical architecture of the human striatum. J Comp Neurol 384:1-25.

-Hontanilla B, Parent A, de las Heras S, GiménezAmaya JM (1998): Distribution of calbindin D-28k and parvalbumin neurons and fibers in the rat basal ganglia. Brain Res Bull 47: 107-116.

Huesa G, Anadón R, Yáñez J (2006): Topography and connections of the telencephalon in a chondrostean, Acipenser baeri: an experimental study. J Comp Neurol 497:519-541.
Jacobowitz DM, Winsky L (1991): Immunocytochemical localization of calretinin in the forebrain of the rat. J Comp Neurol 304:198218.

Jadhao AG, Malz CR (2007): Localization of calcium-binding protein (calretinin, $29 \mathrm{kD}$ ) in the brain and pituitary gland of teleost fish: an immunohistochemical study. Neurosci Res 59:265-276.

Jardon B, Bonaventure N (1992): Plasticity of the frog monocular OKN: involvement of pretectal GABAergic and cholinergic systems. Neurosci Lett 137:189-192.

Jardon BL, Bonaventure N (1997): Involvement of NMDA in a plasticity phenomenon observed in the adult frog monocular optokinetic nystagmus. Vision Res 37:1511-1524.

Jia C, Halpern M (2004): Calbindin D28k, parvalbumin, and calretinin immunoreactivity in the main and accessory olfactory bulbs of the gray short-tailed opossum, Monodelphis domestica. J Morphol 259:271-280.

Jones EG, Hendry SH (1989): Differential calcium binding protein immunoreactivity distinguishes classes of relay neurons in monkey thalamic nuclei. Eur J Neurosci 1:222246.

Kakuta S, Oda S, Gotoh Y, Kishi K (2001): Calbindin-D28k and calretinin immunoreactive neurons in the olfactory bulb of the musk shrew, Suncus murinus. Brain Res Dev Brain Res 129:11-25.

-Kang YS, Park WM, Lim JK, Kim SY, Jeon CJ (2002): Changes of calretinin, calbindin D28K and parvalbumin-immunoreactive neurons in the superficial layers of the hamster superior colliculus following monocular enucleation. Neurosci Lett 330:104-108.

-Kawai Y, Senba E (1999): Electrophysiological and morphological characterization of cytochemically-defined neurons in the caudal nucleus of tractus solitarius of the rat. Neuroscience 89:1347-1355.

Kemppainen S, Pitkanen A (2000): Distribution of parvalbumin, calretinin, and calbindin$\mathrm{D}(28 \mathrm{k})$ immunoreactivity in the rat amygdaloid complex and colocalization with gamma-aminobutyric acid. J Comp Neurol 426: 441-467.

Kerschbaum HH, Hermann A (1992): Calciumbinding proteins in chemoreceptors of Xenopus laevis. Tissue Cell 24:719-724.

-Kiss J, Magloczky Z, Somogyi J, Freund TF (1997): Distribution of calretinin-containing neurons relative to other neurochemically identified cell types in the medial septum of the rat. Neuroscience 78:399-410.

Kosaka T, Kosaka K (2007): Heterogeneity of nitric oxide synthase-containing neurons in the mouse main olfactory bulb. Neurosci Res 57:165-178.

Krutzfeldt NO, Wild JM (2004): Definition and connections of the entopallium in the zebra finch (Taeniopygia guttata). J Comp Neurol 468:452-465.
Kühlenbeck H (1922): Zur Morphologie des Gymnophionengehirns. Jen Med Nat 58: 453-484.

Kühlenbeck H (1975): The Central Nervous Systems of Vertebrates. Basel, Karger, vol 4.

Kühlenbeck H (1978): The Central Nervous Systems of Vertebrates. Basel, Karger, vol 5/2.

-Larson A, Wilson AC (1989): Patterns of ribosomal RNA evolution in salamanders. Mol Biol Evol 6:131-154.

Lee JY, Choi JS, Ahn CH, Kim IS, Ha JH, Jeon CJ (2006): Calcium-binding protein calretinin immunoreactivity in the dog superior colliculus. Acta Histochem Cytochem 39:125138

Legaz I, Olmos L, Real MA, Guirado S, Dávila JC, Medina L (2005): Development of neurons and fibers containing calcium binding proteins in the pallial amygdala of mouse, with special emphasis on those of the basolateral amygdalar complex. J Comp Neurol 488:492-513.

- LeSauter J, Bhuiyan T, Shimazoe T, Silver R (2009): Circadian trafficking of calbindin-ir in fibers of SCN neurons. J Biol Rhythms 24: 488-496.

-LeSauter J, Stevens P, Jansen H, Lehman MN, Silver R (1999): Calbindin expression in the hamster SCN is influenced by circadian genotype and by photic conditions. Neuroreport 10:3159-3163.

Leuba G, Saini K (1997): Colocalization of parvalbumin, calretinin and calbindin D-28k in human cortical and subcortical visual structures. J Chem Neuroanat 13:41-52.

-López JM, Moreno N, Morona R, González A (2006): Distribution of neuropeptide FF-like immunoreactivity in the brain of Dermophis mexicanus (Amphibia; Gymnophiona): comparison with FMRFamide immunoreactivity. Brain Behav Evol 67:150-164.

-López JM, Moreno N, Morona R, Munoz M, Domínguez L, González A (2007): Distribution of somatostatin-like immunoreactivity in the brain of the caecilian Dermophis mexicanus (Amphibia: Gymnophiona): comparative aspects in amphibians. J Comp Neurol 501:413-430.

Lunam CA (1989): Calbindin immunoreactivity in the neurons of the spinal cord and dorsal root ganglion of the domestic fowl. Cell Tissue Res 257:149-153.

-Magnusson A, Dahlfors G, Blomqvist A (1996): Differential distribution of calcium-binding proteins in the dorsal column nuclei of rats: a combined immunohistochemical and retrograde tract tracing study. Neuroscience 73 : 497-508.

Malz CR, Knabe W, Kuhn HJ (2000): Pattern of calretinin immunoreactivity in the main olfactory system and the vomeronasal system of the tree shrew, Tupaia belangeri. J Comp Neurol 420:428-436.

Manteuffel G, Kopp J, Himstedt W (1986): Amphibian optokinetic after nystagmus: properties and comparative analysis in various species. Brain Behav Evol 28:186-197. 
Marín F, Puelles L (1995): Morphological fate of rhombomeres in quail/chick chimeras: a segmental analysis of hindbrain nuclei. Eur J Neurosci 7:1714-1738.

Marín O, Smeets WJ, González A (1997): Distribution of choline acetyltransferase immunoreactivity in the brain of anuran (Rana perezi, Xenopus laevis) and urodele (Pleurodeles waltl) amphibians. J Comp Neurol 382:499534.

Marín O, Smeets WJ, González A (1998): Basal ganglia organization in amphibians: chemoarchitecture. J Comp Neurol 392:285-312.

-Martínez-Guijarro FJ, Freund TF (1992): Distribution of GABAergic interneuronsimmunoreactive for calretinin, calbindin $\mathrm{D} 28 \mathrm{~K}$, and parvalbumin in the cerebral cortex of the lizard Podarcis hispanica. J Comp Neurol 322: 449-460.

-McRitchie DA, Hardman CD, Halliday GM (1996): Cytoarchitectural distribution of calcium binding proteins in midbrain dopaminergic regions of rats and humans. J Comp Neurol 364:121-150.

-Méndez-López M, Méndez M, López L, Arias JL (2009): Spatial working memory learning in young male and female rats: involvement of different limbic system regions revealed by cytochrome oxidase activity. Neurosci Res 65:28-34.

-Milán FJ, Puelles L (2000): Patterns of calretinin, calbindin, and tyrosine-hydroxylase expression are consistent with the prosomeric map of the frog diencephalon. J Comp Neurol 419: 96-121.

Milner AR (1988): The relationships and origin of living amphibians; in Benton MJ (ed): The Phylogeny and Classification of the Tetrapods. Clarendon, Oxford, vol 1, pp 59-102.

Milner AR (2001): Gymnophiona (Caecilians); in Encyclopedia of Life Sciences. London, Nature Publishing Group. http://www.els. net.

Molinari M, Leggio MG, Dell'Anna ME, Giannetti S, Macchi G (1994): Chemical compartmentation and relationships between calcium-binding protein immunoreactivity and layer-specific cortical caudate-projecting cells in the anterior intralaminar nuclei of the cat. Eur J Neurosci 6:299-312.

Morel A, Loup F, Magnin M, Jeanmonod D (2002): Neurochemical organization of the human basal ganglia: anatomofuncional territories defined by the distributions of calcium-binding proteins and SMI-32. J Comp Neurol:86-103.

-Moreno N, Bachy I, Retaux S, González A (2004): LIM-homeodomain genes as developmental and adult genetic markers of Xenopus forebrain functional subdivisions. J Comp Neurol 472:52-72.

Moreno N, González A (2003): Hodological characterization of the medial amygdala in anuran amphibians. J Comp Neurol 466: 389-408.
Moreno N, González A (2004): Localization and connectivity of the lateral amygdala in anuran amphibians. J Comp Neurol 479:130148.

Moreno N, González A (2005): Central amygdala in anuran amphibians: neurochemical organization and connectivity. J Comp Neurol 489:69-91.

Moreno N, González A (2006): The common organization of the amygdaloid complex in tetrapods: new concepts based on developmental, hodological and neurochemical data in anuran amphibians. Prog Neurobiol 78:6190.

Moreno N, González A (2007a): Regionalization of the telencephalon in urodele amphibians and its bearing on the identification of the amygdaloid complex.Front Neuroanat 1:1.

Moreno N, González A (2007b): Evolution of the amygdaloid complex in vertebrates, with special reference to the anamnio-amniotic transition. J Anat 211:151-153.

Moreno N, Morona R, López JM, Domínguez L, Joven A, Bandín S, González A (2011): Characterization of the bed nucleus of the stria terminalis (BST) in the forebrain of anuran amphibians. J Comp Neurol, DOI: $\underline{10.1002 /}$ cne.22694.

Morona R, Ferran JL, Puelles L, González A (2011): Embryonic genoarchitecture of the pretectum in Xenopus laevis: a conserved pattern in tetrapods. J Comp Neurol 519: 1024-1050.

Morona R, González A (2008): Calbindin-D28k and calretinin expression in the forebrain of anuran and urodele amphibians: further support for newly identified subdivisions. J Comp Neurol 511:187-220.

Morona R, González A (2009): Immunohistochemical localization of calbindin-D28k and calretinin in the brainstem of anuran and urodele amphibians. J Comp Neurol 515: 503-537.

Morona R, López JM, Dominguez L, González A (2007a): Immunohistochemical and hodological characterization of calbindin-D28kcontaining neurons in the spinal cord of the turtle, Pseudemys scripta elegans. Microsc Res Tech 70:101-118.

-Morona R, López JM, González A (2006b): Calbindin-D28k and calretinin immunoreactivity in the spinal cord of the lizard Gekko gecko: colocalization with choline acetyltransferase and nitric oxide synthase. Brain Res Bull 69:519-534.

Morona, R, Moreno N, López JM, González A (2007b): Comparative analysis of calbindin $\mathrm{D}-28 \mathrm{~K}$ and calretinin in the retina of anuran and urodele amphibians: colocalization with choline acetyltransferase and tyrosine hydroxylase. Brain Res 1182:34-49.

Morona R, Moreno N, López JM, González A (2006a): Immunohistochemical localization of calbindin-D28k and calretinin in the spinal cord of Xenopus laevis. J Comp Neurol 494:763-783.
Morona R, Northcutt RG, González A (2010): Immunohistochemical localization of calbindin-D28k and calretinin in the spinal cord of lungfishes. Brain Behav Evol 76:198210.

Mühlenbrock-Lenter S, Endepols H, Roth G, Walkowiak W (2005): Immunohistological characterization of striatal and amygdalar structures in the telencephalon of the firebellied toad Bombina orientalis. Neuroscience 134:705-719.

Münkle MC, Waldvogel HJ, Faull RL (2000): The distribution of calbindin, calretinin and parvalbumin immunoreactivity in the human thalamus. J Chem Neuroanat 19:155-173.

Muñoz M, López JM, Sánchez-Camacho C, Moreno N, Crespo M, González A (2001): Comparative analysis of adrenomedullinlike immunoreactivity in the hypothalamus of amphibians. Microsc Res Tech 54:173187.

-Necchi D, Soldani C, Pisu MB, Bernocchi G, Scherini E (1999): Distribution of calretininlike immunoreactivity in the brain of Rana esculenta. J Chem Neuroanat 16:233-243.

-Nemcová V, Petrovicky P, ten Donkelaar HJ (1997): The dorsal tegmentum of the pontomesencephalic junction of the rat - immunohistochemistry (choline acetyltransferase, tyrosine hydroxylase, substance $\mathrm{P}$ ) and NADPH-diaphorase histochemistry in frontal and horizontal sections. J Hirnforsch 38: 231-241.

Nieuwenhuys R (1998): Comparative neuroanatomy: place, principles and programme; in Nieuwenhuys R, ten Donkelaar HJ, Nicholson C (eds): The Central Nervous System of Vertebrates. London, Springer, pp 273-327.

Noble GK (1931): The Biology of the Amphibia. New York, McGraw-Hill.

Northcutt RG (2008): Forebrain evolution in bony fishes. Brain Res Bull 75:191-205.

-Northcutt RG, González A (2011): A reinterpretation of the cytoarchitectonics of the telencephalon of the comoran coelacanth. Front Neuroanat 5:9.

Northcutt RG, Kicliter E (1980): Organization of the amphibian telencephalon; in Ebbesson SOE (ed): Comparative Neurology of the Telencephalon. New York, Plenum Publishing Corporation, pp 203-255.

Nussbaum RA, Wilkinson M (1989): On the classification and phylogeny of caecilians (Amphibia: Gymnophiona), a critical review. Herpetol Monogr 3:1-42.

-Palczewska M, Groves P, Batta G, Heise B, Kuznicki J (2003): Calretinin and calbindin D28k have different domain organizations. Protein Sci 12:180-184.

Parent A, Fortin M, Cote PY, Cicchetti F (1996): Calcium-binding proteins in primate basal ganglia. Neurosci Res 25:309-334.

Parmentier M (1990): Structure of the human cDNAs and genes coding for calbindin $\mathrm{D} 28 \mathrm{~K}$ and calretinin. Adv Exp Med Biol 269:27-34. 
-Parrish-Aungst S, Shipley MT, Erdelyi F, Szabo G, Puche AC (2007): Quantitative analysis of neuronal diversity in the mouse olfactory bulb. J Comp Neurol 501:825-836.

-Pinelli C, D’Aniello B, Fiorentino M, Bhat G, Saidapur SK, Rastogi RK (1997): Distribution of gonadotropin-releasing hormone immunoreactivity in the brain of Ichthyophis beddomei (Amphibia: Gymnophiona). J Comp Neurol 384:283-292.

Polans A, Baehr W, Palczewski K (1996): Turned on by $\mathrm{Ca} 2+$ !: the physiology and pathology of $\mathrm{Ca}(2+)$-binding proteins in the retina. Trends Neurosci 19:547-554.

- Pombal MA, de Arriba MC, Sampedro C, Alvarez R, Megias M (2002): Immunocytochemical localization of calretinin in the olfactory system of the adult lamprey, Lampetra fluviatilis. Brain Res Bull 57:281-283.

- Pombal MA, Puelles L (1999): Prosomeric map of the lamprey forebrain based on calretinin immunocytochemistry, Nissl stain, and ancillary markers. J Comp Neurol 414:391-422.

- Porteros A, Arevalo R, Weruaga E, Crespo C, Briñón JG, Alonso JR, Aijón J (1997): Calretinin immunoreactivity in the developing olfactory system of the rainbow trout. Brain Res Dev Brain Res 100:101-109.

- Price M (1993): Members of the Dlx- and Nkx2gene families are regionally expressed in the developing forebrain. J Neurobiol 24:13851399.

Pritz MB, Siadati A (1999): Calcium binding protein immunoreactivity in nucleus rotundus in a reptile, Caiman crocodilus. Brain Behav Evol 53:277-287.

- Pritz MB, Stritzel ME (1991) Calcium binding protein immunoreactivity in a reptilian thalamic reticular nucleus. Brain Res 554:325328.

Puelles E, Annino A, Tuorto F, Usiello A, Acampora D, Czerny T, Brodski C, Ang SL, Wurst W, Simeone A (2004): Otx2 regulates the extent, identity and fate of neuronal progenitor domains in the ventral midbrain. Development 131:2037-2048.

-Puelles L, Kuwana E, Puelles E, Bulfone A, Shimamura K, Keleher J, Smiga S, Rubenstein JL (2000): Pallial and subpallial derivatives in the embryonic chick and mouse telencephalon, traced by the expression of the genes Dlx-2, Emx-1, Nkx-2.1, Pax-6, and Tbr-1. J Comp Neurol 424:409-438.

-Puelles L, Milán F, Martínez-de-la-Torre M (1996): A segmental map of architectonic subdivisions in the diencephalon of the frog Rana perezi: acetylcholinesterase-histochemical observations. Brain Behav Evol 47: 279-310.

-Puelles L, Robles C, Martínez-de-la-Torre M, Martínez S (1994): New subdivision schema for the avian torus semicircularis: neurochemical maps in the chick. J Comp Neurol 340:98-125.

Puelles L, Rubenstein JL (2003): Forebrain gene expression domains and the evolving prosomeric model. Trends Neurosci 26:469-476.
Rahman FE, Baizer JS (2007): Neurochemically defined cell types in the claustrum of the cat. Brain Res 1159:94-111.

-Rastogi RK, D’Aniello B, Pinelli C, Fiorentino M, di Fiore M, di Meglio M, Iela L (2001): FMRFamide in the amphibian brain: a comprehensive survey. Microsc Res Tech 54: 158-172.

-Rastogi RK, Meyer DL, Pinelli C, Fiorentino M, D’Aniello B (1998): Comparative analysis of GnRH neuronal systems in the amphibian brain. Gen Comp Endocrinol 112:330-345.

Real MA, Pineda D, Dávila JC, Guirado S (2008): Development and adult organization of the lateral part of the bed nucleus of the stria terminalis in the chicken. Brain Res Bull 75: 410-413.

Résibois A, Rogers JH (1992): Calretinin in rat brain: an immunohistochemical study. Neuroscience 46:101-134.

-Riedel A, Hartig W, Seeger G, Gartner U, Brauer K, Arendt T (2002): Principles of rat subcortical forebrain organization: a study using histological techniques and multiple fluorescence labeling. J Chem Neuroanat 23:75104.

Rodríguez-Moldes I, Timmermans JP, Adriaensen D, De Groodt-Lasseel MH, Scheuermann DW, Anadón R (1990a): Immunohistochemical localization of calbindin-D28K in the brain of a cartilaginous fish, the dogfish (Scyliorhinus canicula L.). Acta Anat (Basel) 137:293-302.

Rodríguez-Moldes I, Timmermans JP, Adriaensen D, De Groodt-Lasseel MH, Scheuermann DW, Anadón R (1990b): Asymmetric distribution of calbindin-D28K in the ganglia habenulae of an elasmobranch fish. Anat Embryol (Berl) 181:389-391.

Rogers JH (1987): Calretinin: a gene for a novel calcium-binding protein expressed principally in neurons. J Cell Biol 105:1343-1353.

Rogers JH, Résibois A (1992): Calretinin and calbindin-D28k in rat brain: patterns of partial co-localization. Neuroscience 51:843-865.

-Roth G, Nishikawa KC, Naujoks-Manteuffel C, Schmidt A, Wake DB (1993): Paedomorphosis and simplification in the nervous system of salamanders. Brain Behav Evol 42:137170.

Roth G, Nishikawa KC, Wake DB (1997): Genome size, secondary simplification, and the evolution of the brain in salamanders. Brain Behav Evol 50:50-59.

-Sánchez-Camacho C, López JM, González A (2006): Basal forebrain cholinergic system of the anuran amphibian Rana perezi: evidence for a shared organization pattern with amniotes. J Comp Neurol 494:961-975.

Sánchez-Camacho C, Marín O, ten Donkelaar HJ, González A (2001): Descending supraspinal pathways in amphibians. 1. A dextran amine tracing study of their cells of origin. J Comp Neurol 434:186-208.
Sánchez-Camacho C, Peña J, González A (2003): Catecholaminergic innervation of the septum in the frog: a combined immunohistochemical and tract-tracing study. J Comp Neurol 13;455:310-323.

-San Mauro D, Gower DJ, Oommen OV, Wilkinson M, Zardoya R (2004): Phylogeny of caecilian amphibians (Gymnophiona) based on complete mitochondrial genomes and nuclear RAG1. Mol Phylogenet Evol 33:413-427.

-Schiffmann SN, Cheron G, Lohof A, d'Alcantara P, Meyer M, Parmentier M, Schurmans S (1999): Impaired motor coordination and Purkinje cell excitability in mice lacking calretinin. Proc Natl Acad Sci USA 96:52575262.

Schmidt H, Kunerth S, Wilms C, Strotmann R, Eilers J (2007): Spino-dendritic cross-talk in rodent Purkinje neurons mediated by endogenous Ca2+-binding proteins. J Physiol 581: 619-629.

Schmidt H, Schwaller B, Eilers J (2005): Calbindin D28k targets myo-inositol monophosphatase in spines and dendrites of cerebellar Purkinje neurons. Proc Natl Acad Sci USA 102:5850-5855.

Schmidt A, Wake MH (1991): Phylogenetic changes in the morphological differentiation of caecilian tectum mesencephali; in Elsner $\mathrm{N}$, Penzlin H (eds): Synapse-Transmission Modulation: Proc. 19th Goettingen Neurobiology Conference. Stuttgart, Thieme, $\mathrm{p}$ 335.

Schwaller B, Meyer M, Schiffmann S (2002): 'New' functions for 'old' proteins: the role of the calcium-binding proteins calbindin $\mathrm{D}$ $28 \mathrm{k}$, calretinin and parvalbumin, in cerebellar physiology - studies with knockout mice. Cerebellum 1:241-258.

Shu SY, Ju G, Fan LZ (1988): The glucose oxidaseDAB-nickel method in peroxidase histochemistry of the nervous system. Neurosci Lett 85:169-171.

Smith-Fernández A, Pieau C, Reperant J, Boncinelli E, Wassef M (1998): Expression of the Emx-1 and Dlx-1 homeobox genes define three molecularly distinct domains in the telencephalon of mouse, chick, turtle and frog embryos: implications for the evolution of telencephalic subdivisions in amniotes. Development 125:2099-2111.

Soares JG, Botelho EP, Gattass R (2001): Distribution of calbindin, parvalbumin and calretinin in the lateral geniculate nucleus and superior colliculus in Cebus apella monkeys. J Chem Neuroanat 22:139-146.

Sorvari H, Soininen H, Pitkanen A (1996a): Calbindin-D28K-immunoreactive cells and fibres in the human amygdaloid complex. Neuroscience 75:421-443.

Sorvari H, Soininen H, Pitkanen A (1996b): Calretinin-immunoreactive cells and fibers in the human amygdaloid complex. J Comp Neurol 369:188-208. 
Sperl M, Manteuffel G (1987): Directional selectivities of visual afferents to the pretectal neuropil in the fire salamander. Brain Res 404:332-334

-Stadler F, Schmutz I, Schwaller B, Albrecht U (2010): Lack of calbindin-D28k alters response of the murine circadian clock to light. Chronobiol Int 27:68-82.

Sternberger LA (1979): Immunohistochemistry. New York, Wiley.

Storch V, Welsch U (1973): Zur Ultrastruktur von Pigmentepithel und Photoreceptoren der Seitenaugen von Ichthyophis kohtaoensis (Gymnophiona, Amphibia). Zool Jahrb Abt Anat 90:160-173.

-Straka H, Baker R, Gilland E (2006): Preservation of segmental hindbrain organization in adult frogs. J Comp Neurol 494:228-245.

-Straka H, Gilland E, Baker R (1998): Rhombomeric organization of brainstem motor neurons in larval frogs. Biol Bull 195:220-222.

-Suárez J, Dávila JC, Real MA, Guirado S, Medina L (2006): Calcium-binding proteins, neuronal nitric oxide synthase, and GABA help to distinguish different pallial areas in the developing and adult chicken. 1. Hippocampal formation and hyperpallium. J Comp Neurol 497:751-771.

- Sussel L, Marín O, Kimura S, Rubenstein JL (1999): Loss of Nkx2.1 homeobox gene function results in a ventral to dorsal molecular respecification within the basal telencephalon: evidence for a transformation of the pallidum into the striatum. Development 126 : 3359-3370.

Taylor EH (1968): The Caecilians of the World: Ataxonomic Review: Lawrence, University of Kansas Press. ten Donkelaar HJ (1998a): Urodeles; in Nieuwenhuys R, ten Donkelaar HJ, Nicholson C (eds): The Central Nervous System of Vertebrates. London, Springer, vol 2, pp 10451150.

ten Donkelaar HJ (1998b): Anurans; in Nieuwenhuys R, ten Donkelaar HJ, Nicholson C, (eds): The Central Nervous System of Vertebrates. London, Springer, vol 2, pp 11511314.

Toida K, Kosaka K, Heizmann CW, Kosaka T (1998): Chemically defined neuron groups and their subpopulations in the glomerular layer of the rat main olfactory bulb. 3. Structural features of calbindin D28K-immunoreactive neurons. J Comp Neurol 392:179-198.

Trueb L, Cloutier R (1991): A phylogenetic investigation of the inter- and intrarelationships of the Lissamphibia (Amphibia: Temnospondyli); in Schultze HP, Trueb L (eds): Origins of the Major Groups of Tetrapods: Controversies and Consensus. Ithaca, Cornell University Press, pp 223-313.

Uray NJ, Gona AG (1999): Calbindin immunoreactivity in the auricular lobe and interauricular granular band of the cerebellum in bullfrog. Brain Behav Evol 53:10-19.

-Uray NJ, Gona AG, Sexton PS (1998): Calbindin immunoreactivity in Purkinje cells of the bullfrog cerebellum during thyroxine-induced metamorphosis. Brain Behav Evol 51: 284-290.

Vann SD, Aggleton JP (2003): Evidence of a spatial encoding deficit in rats with lesions of the mammillary bodies or mammillothalamic tract. J Neurosci 23:3506-3514.

-Verney C, Zecevic N, Ezan P (2001): Expression of calbindin $\mathrm{D} 28 \mathrm{~K}$ in the dopaminergic mesotelencephalic system in embryonic and fetal human brain. J Comp Neurol 429:45-58.

-Wang YJ, Liu CL, Tseng GF (1996): Compartmentalization of calbindin and parvalbumin in different parts of rat rubrospinal neurons. Neuroscience 74:427-434.
Wang CZ, Yang SF, Xia Y, Johnson KM (2008): Postnatal phencyclidine administration selectively reduces adult cortical parvalbumin-containing interneurons. Neuropsychopharmacology 33:2442-2455.

-Welsch U, Tan SH (1979): Enzyme histochemical study of the brain of Chthonerpeton indistinctum (in German). Z Mikrosk Anat Forsch 93:689-714.

-Welsh DK, Takahashi JS, Kay SA (2010): Suprachiasmatic nucleus: cell autonomy and network properties. Annu Rev Physiol 72:551577.

Wicht H, Himstedt W (1988): Afferents to the telencephalon in urodele and gymnophione amphibians, with a special note on thalamic organization in Gymnophiones; in Schwerdtfeger WK, Germnoth P (eds): The Forebrain in Nonmammals: New Aspects of Structure and Development. Berlin, Springer, pp 43-55.

-Wild JM, Williams MN, Howie GJ, Mooney R (2005): Calcium-binding proteins define interneurons in HVC of the zebra finch (Taeniopygia guttata). J Comp Neurol 483:76-90.

-Winsky L, Montpied P, Arai R, Martin BM, Jacobowitz DM (1992): Calretinin distribution in the thalamus of the rat: immunohistochemical and in situ hybridization histochemical analyses. Neuroscience 50:181196.

Zardoya R, Meyer A (2001): On the origin of and phylogenetic relationships a mong living amphibians. Proc Natl Acad Sci USA 98:73807383.

Zilles K, Welsch U, Schleicher A (1981): The telencephalon of Ichthyophis paucisulcus (Amphibia Gymnophiona (Caecilia)): a quantitative cytoarchitectonic study. Z Mikrosk Anat Forsch 95:943-962. 